\title{
CONSECUENCIAS PSICOSOCIALES DE LA PARTICIPACIÓN EN ESCENARIOS DE JUSTICIA TRANSICIONAL EN UN CONTEXTO DE CONFLICTO, IMPUNIDAD Y NO-TRANSICIÓN.
}

\author{
PSYCHO-SOCIALCONSEQUENCES OF THE PARTICIPATION IN \\ SCENARIOS OF TRANSITIONAL JUSTICE WITHIN A CONTEXT \\ OF CONFLICT, IMPUNITY, AND NO TRANSITION.
}

Recibido: febrero de 2013 - Revisado: agosto de 2013 - Aceptado: 30 de octubre de 2013

Por: Juan David Villa Gómez. ${ }^{1}$

\section{RESUMEN.}

El siguiente artículo recoge las voces de víctimas de violencia política en tres escenarios geográficos y sociopolíticos: el Oriente Antioqueño, el sur de Córdoba y la ciudad de Medellín (Madres de la Candelaria). A través de relatos de vida y grupos focales, los y las participantes expresaron sus significaciones y experiencias en torno a su participación en escenarios de reparación, verdad y justicia propiciados por el Estado Colombiano (hasta junio de 2012) en el marco de las normas de transición que se han aplicado en un contexto donde no ha finalizado el conflicto armado y se mantienen altos índices de impunidad y coerción de la población civil. Se discuten, a partir de los testimonios, las consecuencias psicosociales que se generan en las personas, desde una mirada compleja, cuando acuden a estos mecanismos propiciados por las normas colombianas. Abordando tanto los efectos de transformación y reparación, como aquellos que producen revictimización. Se concluye con una propuesta de justicia anamnética (Reyes Mate, 2003) que posibilite escenarios que respeten los derechos de las víctimas sin que esto implique revictimización ni obstáculos al logro de la paz.

\section{PALABRAS CLAVE.}

Víctimas del conflicto armado, Intervención psicosocial, Verdad, Justicia, Reparación, Justicia Transicional.

\section{ABSTRACT.}

The following article contains the voices of the victims of political violence in three geographical and sociopolitical scenarios in Colombia: The Eastern area of Antioquia, the Southern area of Cordoba and the city of Medellin (Mothers of the La Candelaria). Through stories of life and groups focus, participants expressed their meanings and experiences related to their participation in scenarios of repair, truth, and justice brought about by the Colombian State (as of June 2012) in the framework of the rules of transition which have been applied, in a context where the armed conflict has not ended yet, and where high levels of impunity and coercion of civilians have been maintained. Based on the testimonies collected, the psycho-social consequences generated in people, from a complex look, when they make use of these mechanisms supported by the Colombian standards, are discussed in this article. It addresses the transformation and the repair effects as well as those which cause re-victimization. As a conclusion, it proposes an anamnestic justice (Reyes Mate, 2003) which makes possible the respect of the rights of victims, without implying revictimization or obstacles to the achievement of peace.

\section{KEY WORDS AND EXPRESSIONS:}

Armed conflict victims; Psycho-social intervention; Truth; Justice; Reparation; and Transitional Justice.

\footnotetext{
${ }^{1}$ Psicólogo - Pontificia Universidad Javeriana, Magister y Doctor en Cooperación Internacional al Desarrollo Universidad Pontificia de Comillas, Madrid, España. Docente Investigador Universidad de San Buenaventura Medellín-Colombia.Juand.villa@usbmed.edu.co.
} 


\section{Introducción y método.}

El presente texto emerge del proceso de investigación que desarrollé con comunidades y organizaciones de víctimas del conflicto armado en el Oriente Antioqueño, el sur del departamento de Córdoba y la ciudad de Medellín, que tuvo como resultado la tesis doctoral: "El papel de la memoria colectiva en la reconstrucción del tejido social y el empoderamiento colectivo de las víctimas". Este trabajo investigativo se desarrolló a través del método autobiográfico con 62 relatos de vida recogidos en entrevistas en profundidad y complementados con 19 grupos de discusión desarrollados para comprender el sentido de las acciones públicas de memoria colectiva que realizan estas agrupaciones de víctimas. En la investigación se analizaron categorias relacionadas con la transformación subjetiva (en el nivel emocional, cognitivo y comportamental), estrategias de afrontamiento, cohesión social, participación y construcción de ciudadanía.

En la discusión de esta última categoría, emergió como categoría complementaria, dentro de la investigación, una reflexión de los y las participantes en torno a sus acciones concretas de reivindicación de derechos y ejercicio de su ciudadanía en el marco jurídico que el Estado colombiano ha creado como normas para asumir una "transición sin posconflicto", que implica acciones relacionadas con la verdad, la justicia y la reparación de las víctimas, en un marco de altos niveles de impunidad y mantenimiento del conflicto armado. Así pues se han constituido las siguientes normas que abordarian la restitución de derechos a las víctimas: ley 975 de 2005 (Justicia y paz), decreto 1298 de 2008 (reparación administrativa), y ley 1448 de 2011 (ley de víctimas).

En este sentido este texto es una profundización del texto desarrollado en el número 13-I de esta misma revista, que implica una reflexión sobre los procesos de reparación, verdad y justicia que han emergido en Colombia en los últimos años y se convierte en un abrebocas de muchas preguntas para realizar una investigación a fondo de la aplicación de la ley 1448 de 2011 (Ley de víctimas). ${ }^{2}$

El presente análisis se realiza desde un enfoque y una perspectiva psicosocial utilizando como enfoque investigativo la fenomenología hermenéutica. Se desarrollaron relatos de vida con entrevistas en profundidad a 32 personas (26 mujeres y 6 hombres) del Oriente Antioqueño, 13 personas del sur de Córdoba (10 mujeres y 3 hombres) y 13 madres de la candelaria; 4 historias de vida a mujeres de las tres regiones estudiadas; 19 grupos de discusión con participantes de los procesos de víctimas de las tres regiones, 6 entrevistas semiestructuradas con participantes externos a los procesos de víctimas y 9 cuestionarios a expertos que han trabajado en intervenciones sociales en los contextos referidos.

Todos estos relatos fueron transcritos y fueron analizados por el método de análisis categorial por matrices, partiendo de un análisis intratextual, donde cada relato fue cruzado con las categorias construidas en la investigación; luego un análisis intertextual que permitía cruzar los relatos de los y las participantes según cada categoría. En este proceso aparece como categoría emergente las "consecuencias psicosociales de la participación en escenarios de verdad, justicia y reparación". Estos relatos fueron codificados en dos niveles de acuerdo al método de codificación axial que implica una "depuración y diferenciación de las categorías (conceptos) derivadas" (Flick, 2004), en una relación que va de lo general a lo particular, de los conceptos centrales a los conceptos derivados y marginales; de lo que tiene mayor poder explicativo hacia lo que es ejemplo o desarrollo teórico. 
Con el material codificado y disponible, se elabora el texto del presente artículo, en el cual se hace visible la voz del investigador, proponiendo interpretaciones, hipótesis, desarrollos conceptuales, que a la vez se ilustran con los relatos de los y las participantes. Se da un proceso de selección de relatos que puedan dar cuenta de los principales constructos teóricos e interpretativos que se han ido construyendo a partir de una pregunta sustancial que emergió en la investigación: ¿Han sido los actos públicos de memoria y la construcción de una memoria colectiva factores que han jugado un papel en la construcción de una perspectiva de la ciudadanía de derechos que posibilite la lucha contra la impunidad y el reclamo efectivo de los derechos a la verdad, la justicia y la reparación?

Una de las grandes contradicciones es que Colombia ha pretendido construir un marco jurídico de justicia transicional en un país donde el conflicto armado no ha terminado y las violaciones a los derechos humanos y al derecho internacional humanitario siguen vigentes día a día. Por lo tanto, aun cuando desde un marco de análisis de justicia transicional, a la luz del Derecho internacional de los derechos humanos, el derecho internacional de las víctimas y el marco normativo internacional que protege los derechos de las víctimas, pueda decirse que la legislación colombiana muestra algunos avances según los estándares internacionales; si se analiza con más detenimiento, puede observarse una intencionalidad de tener marcos formales, con pocas aplicaciones en términos de acceso a la justicia para las víctimas, sanción a los responsables, lucha efectiva contra la impunidad y garantías de no repetición. ${ }^{3}$ Este análisis es un tema profundo y muy amplio, que sería asunto de una investigación jurídica. Sin embargo, vale como marco y fondo, porque al final los relatos de los y las participantes, víctimas/sobrevivientes, dan cuenta de estas falencias, ambigüedades y trampas de esta legislación.

Una última acotación: los y las participantes han utilizado los escenarios y mecanismos abiertos por el Estado, porque les permite un mínimo de garantías, en un contexto de inseguridad y control de grupos armados ilegales, además de las restricciones que el mismo Estado impone cuando se trata de acciones violatorias de los derechos humanos ejecutadas directamente por agentes estatales. De todas formas, víctimas que han salido de la anomia y el anonimato a la palestra pública, porque han vivido una experiencia de transformación emocional, que no contaban con un discurso político previo ni con la formación suficiente para pelear por sus derechos, hacen parte de procesos que aún están en desarrollo, y que necesitan apoyo externo, mayor formación y capacitación, mayor asesoría jurídica y legal; y finalmente, respaldo social y político.

\section{Resultados.}

"Yo como que estaba comiéndome a mi propia hija...": Contradicciones de la reparación sin verdad nijusticia

Comienzo por la reparación, porque, de acuerdo con la legislación colombiana, parece que es prioritaria dentro de la intención de garantizar los derechos de las víctimas. Ahora bien, también parece que el proceso se ha centrado en la denominada "reparación administrativa" que consiste en dar una "ayuda económica" que denominan indemnización (calculada en el marco de la ley 1448, según el tipo de victimización, el daño y el tamaño de la familia), con lo que se pretende "compensar" a las víctimas por los daños y perjuicios, pero que no logra satisfacer necesidades mínimas de la gente, como se verá más adelante. De otro lado, pareciera que la otra cara de la reparación es la ayuda psicosocial, tal como se enunció en un artículo del número anterior de esta revista. 
...lo que están haciendo por las víctimas, para mí, eso son pañitos de agua tibia... porque para que a mí me pongan un psicólogo, entonces tienen que pagarle al psicólogo y tienen que girar unos recursos, y los otros recursos yo no sé para dónde se van... y así pasan todo... Pero vea, al desplazado le dan una miseria aquí, este año, el otro año le dan otra miseria y a la víctima le dan esos 20 millones y ya pare de contar, ¿y entonces? Seguimos con la misma falencia... (Madres, E13)

Como puede observarse, este tipo de "ayuda" no genera los efectos compensatorios que las víctimas necesitan para transformar su condición de vida, sino que por el contrario terminan siendo paños de agua tibia, paliativos con los que la gente ni experimenta reparación ni siente que se transforme su condición actual ni su subjetividad.

La pregunta que surge es: ¿estas "indemnizaciones" tal como se dieron, por lo menos hasta la mitad del año inmediatamente anterior (2012), son en efecto reparadoras? ¿Por qué, según lo afirmado por las víctimas en esta investigación, ${ }^{4}$ el Estado estaba pensando que con dar un dinero estaba cumpliendo con su papel como garante de la reparación? ¿Cuál es la intencionalidad que podria rastrearse allí? Los testimonios y relatos de los y las participantes que buscan esta reparación, de los que no la han recibido y de quienes la recibieron permiten evidenciar este imaginario:

... a mí la reparación administrativa (indemnización) me parece una mentira, porque, cuando hablamos de dinero es lo peor que le puede pasar a uno, porque el Estado cree que con dinero va a callar las voces de las víctimas y eso no es así. Porque es un deber del Estado, es un derecho que tenemos, pero es que es un derecho global: si el Estado le va a dar a una víctima un dinero por qué no mira en qué entorno vive, cuál es la situación de la familia para después llegar con el dinero, entonces a mí eso me parece una farsa, no, eso no es una reparación eso es una farsa... ....según ellos a pagar las víctimas, como si las víctimas tuvieran un precio, como si a uno el esposo y el dolor, y la rabia y los sufrimientos se los pudieran pagar ¡no! (Oriente, E6)

Así pues, esta es la primera gran inquietud que experimenta la gente: ¿Mi ser querido tenía un precio? ¿El Estado quiere callar a las víctimas con dinero para que no reclamen verdad y justicia? Hay muchas dudas al respecto entre los y las participantes. También aquí cabe preguntarse por la ley de justicia y paz: ¿Los llamados incidentes de reparación en el marco de esta ley lo están logrando? En este último punto, de acuerdo con Forer (2011), no se ha dado siquiera un "incidente" de reparación en el contexto de esta ley que ya tiene 8 años de haber sido promulgada. Por lo tanto, en términos estrictos de reparación no se está logrando siquiera satisfacer este derecho:

...a las víctimas, primeramente no se les está reconociendo el derecho que ellos tienen a la verdad, la justicia y la reparación; y que prácticamente siguen desconfiando del Estado, porque no está generando confianza, que pueda uno decir como víctima: es que el Estado verdaderamente me estaba viendo mis derechos... el Estado me está teniendo en cuenta como víctima y gracias al Estado yo estoy saliendo adelante... yo creo que no está pasando nada de eso. (Madres, E5)

De acuerdo con Martín Beristaín (2006, 2009, 2010), Gómez Isa (2008); Hayner (2008) y la misma ley 1448 de 2011, entre otros, existen diferentes tipos de reparación:

A 
- "La restitución, que busca restablecer la situación previa de la víctima". Incluye entre otras cosas, el restablecimiento de derecho, el retorno a su lugar de residencia, devolución de bienes y empleo.

- La indemnización, se refiere a la compensación monetaria por daños y prejuicios, tanto daño pecuniario como moral (miedo, humillación, estrés, problemas mentales, reputación, etc.).

- La rehabilitación, que incluye medidas tales como la atención médica y psicológica, así como servicios legales y sociales.

- Las medidas de satisfacción, como la verificación de los hechos y conocimiento público de la verdad, restauración de derechos y actos de desagravio; sanciones contra perpetradores, conmemoración y tributo a las víctimas.

- Las garantías de no repetición incluyendo el cese de las violaciones, reformas institucionales y legales que promuevan cambios en los servicios de seguridad y promoción de derechos humanos, etc.

Si estos procesos se cumplen de forma clara y manifiesta y, sobre todo, si se produce una satisfacción a la víctimas, se puede lograr revertir la asimetría de poder entre el victimario y la víctima, lo cual implica realmente un proceso reparador (Paéz, 2010; Paéz \& Liu, 2010). Sin embrago, en un contexto de dominación y explotación de las víctimas por parte de los victimarios y sus cómplices, en un contexto de impunidad, como el que aún se sigue manteniendo en buena parte del territorio nacional, las reparaciones, sobre todo cuanto tienen un tinte centrado en lo material, pueden traer consecuencias negativas para las mismas víctimas, como pérdida de la autoestima, de la confianza y de la esperanza, (Yzerbit \& Demoulin, 2010), beneficiando al grupo dominador (Barkan, 2000) alterando, en algunos casos, los procesos de recuperación emocional. Este parece ser el contexto que se está dando en Colombia:

...a pesar de que yo no he recibido ninguna ayuda por este lado, he visto personas que se han sentido sucias recibiendo ese dinero... hay personas que han sabido emplear su dinero, supongamos dentro de mi asociación hay una de las mujeres que recibió la famosa reparación del Estado, se compró una casa, y cada que ella entra a su casa dice: "me estoy parando en mi hijo", porque el Estado cree que con darle 15 o 20 millones $^{5}$ con eso va a reparar una víctima... iy no, no es así! (Oriente, E6)

Además de ello, en el caso colombiano, la reparación se está dando a las víctimas en un contexto donde no hay verdad y se deniega la justicia. Es decir, en un clima de impunidad, que no posibilita que la reparación tenga realmente los efectos esperados. De acuerdo con Hamber, Nagen \& O'Malley (2000), Martín Beristain (2008, 2010) y Gómez Isa (2008), un proceso de reparación que no se acompañe de verdad y justicia, es un proceso en el cual se puede ofender aún más a las víctimas, puesto que éstas pueden sentir que se está comprando su silencio:

...yo creo que eso es una trampa porque después cuando la gente reciba esa reparación, nos van a decir que ya no somos víctimas, y ya no nos van a reparar, y esa reparación no abarca todo lo que perdimos. Dicen que para que haya una reparación integral me tienen que 
restituir lo que yo tenía antes, ¿y cómo me van a restituir lo que yo tenía antes? Por ejemplo, yo perdí años como desplazada, yo perdí un empleo que tenía, con el cual sostenía mis hijos; en este momento yo no soy la que sostengo mis hijos, sino que mi niña mayor es la que lucha por ayudarme a sostener esos niños, entonces ¿cómo me van a restituir a mí? Si es volver a un estado como estaba antes, es muy difícil, porque mire todos los años que pasaron, yo ya no voy a tener las fuerzas para trabajar allá donde estaba... (Oriente, E1)

Ahora bien, los y las participantes en esta investigación se ubican en una dinámica pragmática que parte de un análisis simple. El Estado ha generado mecanismos legales para reclamar un dinero con el que no se contaba, en un contexto donde no se tiene confianza en el Estado y las relaciones con el mismo y el acceso a los servicios sociales están mediados por relaciones clientelares (González, et al., 2002; Villa, 2012). En este contexto, la gente prefiere hacer la gestión, reclamar el dinero, resolver necesidades básicas, puesto que la mayoría viven en condiciones de pobreza extrema, y asumir lo que la ley dice; puesto que suponen que si no "toman" este dinero, quedará regado en las redes de corrupción del país, se quedará en otras manos y se "perderá". Así pues, se acepta la transacción, porque no se espera tampoco más.

Esta mirada pragmática lleva a la gente a realizar un razonamiento para analizar en qué se puede invertir el dinero para intentar solucionar necesidades apremiantes de vivienda, salud, educación, e incluso alimentación o trabajo. Por esta razón se realiza todo el procedimiento y se lucha por contar con este dinero:

...supuestamente la estoy esperando, yo metí papeles... yo no he pensado nada, porque está demorado, estoy tranquila, pues si llega está bien y si no llega qué se va a hacer... y si llega, pues será coger esa plata que nos da el gobierno y saberla emplear en alguna cosa, de manera que pueda poner yo algún negocio que me permita seguir trabajando y no tener que seguir yendo a trabajar en casas de familia, para ver si dejo de sufrir en esos trabajos, tan duros... el pensado mío es arreglar mi casita porque está muy caída y poner un negocio pequeño, para ya no tener que trabajar más... claro que esa plata no repara lo que ha pasado, esa plata no me repara a mi hijo, porque yo quisiera 1000 veces tener a mi muchacho y no saber que tengo una plata y que no tengo a mi muchacho... (Madres, E3)

De una u otra forma una reparación centrada en lo económico, tal como la percibe la gente en esta investigación y, por lo menos, hasta el año anterior, no toma en cuenta las complejidades del contexto, con las consecuentes experiencias revictimizadoras para la gente. Por eso, hay que afirmarlo categóricamente: cuando se hace sin un marco de integralidad, no es una acción realmente reparadora: ${ }^{6}$

¿Quién dijo que un ser humano tiene precio? O al menos para mí $\mathrm{H}$. vale montonera... entonces yo creo que la reparación para mí es saber la verdad, poderle darle algún día una cristiana sepultura, saber dónde está, qué pasó... ésa sería la reparación... yo creo que esa plata no es nada y yo creo que cada cual va trabajando por sus propias cosas... entonces no se trata que otro me dé lo que mi hermano valía, porque eso no justifica nada ni repara nada... (Madres, E12) 
De otro lado, y en relación con una construcción precaria de ciudadanía de derechos por parte de buena cantidad de las víctimas de violencia política en Colombia, la mirada de sí mismos/as como "receptores" de ayuda de parte del Estado, especialmente en las bases sociales de los colectivos analizados, la búsqueda y recepción de este dinero no se logra analizar ni se logra reflexionar sobre los términos de la relación e interlocución con el Estado. No se logra comprender como una lucha y una reivindicación por los derechos, sino que se recibe como una "ayuda", a la manera de un subsidio, con la que no se contaba, ante la cual se deben hacer los trámites pertinentes; pero que no repara en realidad ni implica una acción de justicia restaurativa ni distributiva por parte del Estado, se recibe más como una "caridad":

Hay gente que dice que ellos no quieren plata, yo si la quiero porque si yo tuviera a mi esposo vivo mis hijos no hubieran estado sufriendo tanto, que sea lo que sea pero yo la recibo. Yo la siento como una ayuda, eso se me acaba porque ya casi no tengo nada, porque la he ido gastando y para eso es, para favorecerse uno por un tiempo, como los subsidios. Pero cuando a uno le dan la plata a uno sí se le viene a la mente la memoria de qué es lo que está recibiendo y eso le duele a uno... fuera mejor que la persona estuviera ahora... porque al final el Estado nos da eso como una obra de caridad que hace con una víctima, pero un rato, un momentito. (Oriente, E17)

Las demandas de reparación económica, de todas formas, suelen ser fundamentales para las víctimas, especialmente si son aquéllas que están en condiciones de pobreza y exclusión social extrema; en el caso de los y las participantes en esta investigación, 76\% de las personas entrevistadas, se convierte en una necesidad apremiante recibir algún tipo de recurso económico, aún cuando no se logre compensar siquiera una pequeña proporción de lo perdido.

Ahora bien, también esta lógica puede generar incluso competencia y utilización política de las víctimas, que se debaten entres las demandas de dignificación y justicia y las demandas de satisfacción de necesidades básicas (Gómez Isa, 2008). Se trata por tanto de procesos que no recogen la experiencia de la gente, ni su dignidad, ni sus necesidades reales, ni tienen un marco de garantía de derechos. Pero aún, sabiendo todo esto, teniendo claro que es una ayuda, "una caridad" que da el Estado, casi una limosna, la gente la recibe como su única posibilidad de afrontar una situación de pobreza extrema, que entre otras cosas ha sido consecuencia de la violencia padecida.

Tal como se vivió en Guatemala (Mack, 2007; Viaene, 2008): la reparación que no asume la integralidad de la persona, que se centra en el pago de un monto económico, sin valorar los contextos y los hechos, que se complementa con una atención psicológica, en muchos casos limitada al malestar emocional y psíquico, sin abordar los contextos, las injusticias estructurales, la dignidad de la gente y su empoderamiento; termina, al final, generando la sensación de deslealtad con el ser querido que ha sido victimizado, o un malestar (emocional, físico, social y político) que puede ser peor que la misma solución planteada. Al final es como si se legitimara la violencia, no se sancionara lo que pasó, la impunidad queda reinante y las víctimas en un lugar de no reconocimiento o de una visibilización mediática que no implica transformaciones profundas, ni subjetivas ni en las estructuras sociales y políticas:

La plata es una ilusión, lo único que yo hice, bueno, fue que le compré ropita a los niños porque los tenía muy llevados, muy mal vestiditos y les di comida un buen tiempecito... y ya, ahí quedé... y no me sentí bien recibiéndola porque lo primero que hice yo fue un mercado, 
supremamente bueno y grande, yo me comía un pedacito de carne, y yo me sentía que me estaba comiendo a mi hermano... Esa carne me sabía como si fuera humana. ¿Por qué? porque no estaba preparada psicológicamente... entonces esa reparación administrativa sirve para muchas cosas y a mí me suplió necesidades... pero eso no es reparación, es un recurso económico, un ser querido no se renueva, no tiene precio, un ser querido no se repara con nada... (Madres, E1)

Por todo esto, para Martín Beristain \& Pérez Sales (2008) las medidas de reparación deben partir más de las demandas de la gente y no pueden extrapolarse de un contexto a otro, puesto que esto puede implicar también un daño a las víctimas. En el caso de algunos y algunas participantes en esta investigación, la experiencia de recibir la reparación ha resultado verdaderamente traumática. Puede afirmarse que se vive una experiencia de revictimización:

...a mí me llegó una reparación de la hija... pero yo estuve súper mal, yo como que no me explicaba yo por qué recibí esa plata... porque yo pensaba que yo con esa plata como que estaba comiéndome a mí propia hija... yo sentía eso... comiéndome mi propia hija... Yo sufrí mucho por eso... y ha sido porque la niña mía llegaba de Medellín y eso me arreglaba la ropa, dejaba el revuelto pelado, la casa arreglada, y a ella no le gustaba que yo lavara a mano, le daba pesar de mi, porque yo he sufrido mucho de las manos y ella siempre me lavaba la ropa... yo con esa plata le dije a mis hijos que compraran una lavadora, yo pongo a lavar esa lavadora y para mí es un tormento, cada que pongo a lavar esa lavadora a mí ahí mismo me agarran los nervios (lo dice con llanto)... yo pienso en mi hija, y me pongo muy mal; yo misma me digo pero yo sí soy boba, pero me pongo mal, es que es un recuerdo constante... (Oriente, E14)

Como puede observarse se repiten pensamientos obsesivos y recuerdos intrusivos, se experimenta una pérdida de control, la memoria surte, en este caso un efecto contraproducente, puesto que aquí el recuerdo no posibilita una resignificación, sino un volver sobre los hechos desde la culpa, el dolor y la desolación. Por estas razón también el recibir este dinero se puede experimentar como una humillación, lo que muchas veces facilita que termine dándosele el significado que se le da al llamado "dinero fácil": se gasta rápidamente, para evitar el dolor de tenerlo en las manos, ya que la sensación es que el ser querido no tiene valor para el Estado, pero al recibir el dinero la experiencia también se vive como que ha perdido valor para la persona sobreviviente y esto se vive, en algunos casos con gran culpa. De tal manera que tampoco tiene un efecto reparador, sino que afecta a las personas que lo reciben.

Los efectos, en algunos casos, especialmente en situaciones de desaparición forzada ${ }^{7}$ pueden terminar siendo devastadores en términos personales y familiares. En último término el recibir este dinero es vivido por la mayoría de los y las participantes en esta investigación (los que han recibido esta reparación) con una gran contradicción que toca lo emocional, lo moral y lo comportamental:

...por una parte me sentí bien, por otra parte me sentí mal. A ver cómo te dijera yo, es un poco dificil, porque es una contradicción que uno vive, no encuentro palabras para explicar: me sentí bien en lo económico; por ejemplo, construí dos pisos, me compré un carrito para poner fritanga, que siempre habíamos soñado con mi hijo, entonces también se cumplió ese sueño, en eso me sentí bien. Pero también me sentí mal en no estar con él, porque yo en mi mentalidad alcanzaba a pensar, que esto me daba una satisfacción económica y todo, pero si 
estuviera con él, al menos estaríamos los dos luchando en otras cosas más diferentes... (Madres, E8)

En lo emocional, se cruzan el dolor, la culpa y la rabia, con la alegría de poder tener un dinero para suplir necesidades hace años sentidas. En lo moral, se cruza el razonamiento sobre un derecho que se tiene, el tomar lo poco que el Estado da ahora, porque más adelante no se sabe, y asumiendo desde la desesperanza aprendida que tal vez es lo único que se les pueda reconocer, con el sentimiento moral de traición al ser querido, de haberle vendido o haber negociado su dignidad o la propia. Finalmente en lo comportamental, porque se cruza el ejercicio cuidadoso de un gasto que suple la necesidad mencionada, o el gasto compulsivo que implica la sensación de haber recibido un dinero que "está sucio", un dinero que no compensa para nada la experiencia de sufrimiento vivida ni la pérdida del ser querido. En este sentido y desde una perspectiva más amplia, psicosocial, tal como se ha abordado en esta investigación, se hace necesario decir que esta experiencia, en estas condiciones, puede ser contraproducente para la recuperación emocional y de la dignidad de las víctimas. Y que tiene altos riesgos de no ser reparadora y no contribuir a la transformación subjetiva ni a la reconstrucción del tejido social.

Este tipo de experiencia también puede agudizar el fatalismo y la indolencia (Martin- Baró, 1991) que se vive en relación con el Estado y la propia vida. Es decir, se terminan revirtiendo algunos procesos y pasos alcanzados dentro de las asociaciones, tanto en términos de "resignación" y desesperanza aprendida, como en términos de perder la posibilidad de empoderarse como sujetos de derecho. Dentro de esta dinámica, algunas personas logran hacer un proceso de racionalización que les permite comprender la situación: tomar el dinero porque se necesita, realizar un acompañamiento y un diálogo familiar, asumir el dolor que genera, saber que es una "indemnización" insuficiente que ofrece el Estado, pero que se toma, a pesar del dolor que va generando, porque no se deja de sentir que es como si estuvieran vendiendo al ser querido:

...para nosotros ese día fue un día de dolor, un día de duelo... sentíamos como que con plata nos estaban comprando ese ser querido; pero finalmente dentro del mismo proceso de duelo hablamos de eso y dijimos: es muy doloroso porque volvemos a revivir el momento de dolor, pero también es un momento muy legítimo, porque aquí el gobierno no nos está pagando nuestro ser querido, está dando una indemnización por lo que ellos dejaron de hacer, por lo que el mismo gobierno dejó de hacer para cuidar a nuestros seres queridos; y también para no sentir tanto dolor lo vimos así. Y mi niño que nunca conoció a su papá, que quedó de dos meses de gestación me dijo: "¿y usted cree mami que a mí con \$3.333.000 me van a pagar el no haber conocido a mi papá?” Entonces era muy doloroso escuchar eso, si eso es reparación, no me siento reparada en lo más mínimo; y sé que lo debía de recibir porque era un recurso que me hacía falta y sé que tenía derecho a él, pero no me siento reparada con eso, en ningún momento me siento reparada... (Oriente, E20)

Como lo afirma esta participante, que logra hacer un proceso de reflexión al respecto, la situación no debería quedarse de esta manera. Se tendría que hacer un poco más, se tendría que fortalecer la misma acción pública de memoria. Sin embargo, y mientras tanto, la gente sigue recibiendo esta "reparación administrativa" como una forma de compensar esas necesidades, mientras las otras acciones del Estado siguen un paso lento, sin involucrar plenamente a las comunidades y a las víctimas, más con el afán de cumplir indicadores y cifras útiles para campañas de gobierno, pero poco reparadoras, en lo concreto, para las víctimas. 
De otro lado, esta experiencia, puede al mismo tiempo, generar una contracara: que las personas insistan en la búsqueda de satisfacer lo que consideran su derecho, pero al mismo tiempo aumentar la valoración por el proceso que han vivido con sus organizaciones, el apoyo mutuo, la movilización pública de la memoria, la organización, la visibilización de su realidad, al que consideran una forma de reparación desde abajo. E incluso algunos que han recibido esta reparación administrativa pueden llegar a hacer la comparación y reconocen que el proceso de memoria colectiva ha sido más reparador y más sanador para su experiencia personal:

La verdad a mí lo que me ayudó es el proceso de abrazos (Grupos de apoyo en el Oriente Antioqueño desarrollados por las promotoras de vida y salud mental) y la organización de víctimas y las acciones de memoria, porque antes yo me sentía muy triste y ahora estoy mejor, antes no quería hablar con nadie y ahora puedo salir y hablar... (Oriente, E29)

Toda la mirada que se ha realizado en torno al reconocimiento público, la memorialización, el acompañamiento psicosocial, la acción pública de memoria tiene un importante papel en la reparación del sufrimiento de las víctimas, como una forma de reconocerles como seres humanos con su propia dignidad, como sujetos de derecho que han sufrido la vulneración de los mismos, que por lo tanto necesitan restitución (Hamber \& Wilson, 2002; Vandegiste, 2003). Por tanto la memoria se convierte en un puente entre el pasado y el futuro que permite la sanación y la recuperación. Y finalmente puede implicar un proceso de reparación desde abajo, que puede surtir más y mejores efectos que la mal llamada reparación que hasta ahora está realizando el Estado Colombiano.

La clave de un proceso de reparación no está tanto en lo que se haga: si se da una indemnización o se construye un monumento o se hace alguna restitución. La clave está en la forma: que la indemnización no sea una compra ni una transacción, que no prime el cumplimiento de metas cuantitativas o el cumplimiento de indicadores tecnocráticos, sobre la experiencia concreta de la gente; que los monumentos no sean una forma de pasar la página rápido. Siempre, y en todo momento, la clave está en el reconocimiento público, social y moral que se haga de las víctimas. Por esta razón, Hamber $(2002,2011)$ afirma, por su experiencia con grupos de víctimas en Sudáfrica, que en ausencia de reparación, de justicia y en un escenario donde las verdades todavía son incompletas o no se dan, es fundamental realizar un trabajo desde abajo, fortaleciendo las comunidades, haciendo apoyo mutuo, construyendo símbolos, monumentos, realizando rituales y movilizaciones para que la dignificación venga, por lo menos desde la comunidad, y la recuperación emocional de las víctimas no dependa de los juegos de poder político. Este ha sido precisamente el proceso que se documentó en mi tesis doctoral (Villa, 2012), y del que espero poder ofrecer algunas publicaciones próximamente, y que según Kiza et. al. (2006) aún hay poca evidencia empírica al respecto y se hace necesario documentar para definir cuáles serian las acciones concretas que resultan reparadoras para la gente, según los diversos contextos culturales:

...yo creo que es el primer complemento, si no hay memoria cómo va a saber otro lo que le pasó a uno; por ahí empieza la reparación, desde la memoria; porque si uno no cuenta lo que pasó, cómo le van a dar algo, cómo voy a tener yo talleres, cómo voy a tener capacitaciones, si nadie sabe que yo soy víctima cómo me van a llamar a una capacitación o ayudarme a elaborar el duelo... (Oriente, E10) 
Todas las acciones rituales, públicas y performativas realizadas por múltiples comunidades en Colombia, y en concreto por las mujeres del Oriente Antioqueño, las Madres de la Candelaria y las agrupaciones de víctimas en el sur de Córdoba, tienen una dimensión reparadora desde abajo. Las comunidades, las organizaciones sociales de base, las víctimas se organizan para que los hechos no queden en el olvido, para que la dignidad de sus seres queridos, de sus vidas y de sus luchas queden restituidas de alguna manera en el escenario social. Son acciones de memoria que pretenden nombrar lo oculto, elaborar los dolores padecidos y darle algún sentido al horror sufrido en actos de resistencia que dignifican y generan transformaciones en la subjetividad de los y las participantes, como también en la reconstrucción del tejido social. Y son acciones de reparación desde abajo.

Esto no puede compararse con los monumentos, museos y otras acciones "simbólicas" con las que pretende reparar el Estado colombiano, precisamente porque se hacen desde un lugar de no reconocimiento de éste como actor del conflicto y en un marco de denegación de la verdad y la justicia, en algunos casos con intervención psicosocial que, no solamente es insuficiente (ICTJ, 2010), sino que además puede terminar siendo ofensivo para las víctimas, porque se puede considerar como una forma de hacer reparación y memoria borrando el pasado, es decir, constituir una memoria mitica que no identifica responsables, que no sanciona, que no da lugar a la verdad y que no repara integralmente, puesto que además, no ofrece ninguna garantía de no repetición, puesto que en el poder se mantienen los actores que estuvieron detrás de ejércitos de muerte.

Hay una diferencia muy grande entre las acciones que las comunidades han tejido a lo largo y ancho del país, para hacer memoria, incluso para sentir que la reparación es un asunto que les compete y en algunos casos, que si no trabajan en su propia reparación, el Estado poco hará; con los monumentos y "reparaciones simbólicas" que se pretenden realizar desde diversas instancias estatales, que pueden terminar siendo una forma de construcción de "la historia oficial".

Recogiendo lo visto en la presente investigación y cruzándolo con las investigaciones y propuestas de diversos autores, se puede establecer un cuadro comparativo entre las posibilidades que se abren y los límites cuando se aplica un modelo de reparación concreto (Tabla No. 1). La reparación integral propuesta por los actores sociales en un marco de derechos humanos y en una perspectiva internacional. La reparación desde abajo, realizada por las mismas comunidades, como un modelo de afrontamiento y resistencia en medio de una situación precaria de garantía de derechos. Y finalmente el modelo que por lo menos hasta mediados del 2012 (año en que se cerró la recolección de información de esta investigación) ejecutaba el Estado Colombiano, centrado en la entrega de un recurso económico y algunas intervenciones psicológicas no contextualizadas. 


\begin{tabular}{|c|c|c|}
\hline \multicolumn{3}{|c|}{ Tabla No. 1 Comparación entre tres modelos de reparación } \\
\hline $\begin{array}{l}\text { Reparación Integral } \\
\text { Perspectiva del derecho } \\
\text { internacional }\end{array}$ & $\begin{array}{l}\text { Reparación desde abajo } \\
\text { en contextos de } \\
\text { impunidad }\end{array}$ & $\begin{array}{l}\text { Reparación en } \\
\text { impunidad / Reparación } \\
\text { centrada en lo económico. }\end{array}$ \\
\hline $\begin{array}{l}\text { 1. Tiene en cuenta la } \\
\text { dimensión emocional, por } \\
\text { lo tanto se preocupará por } \\
\text { realizar intervenciones } \\
\text { psicosociales que } \\
\text { impliquen el } \\
\text { empoderamiento, la } \\
\text { recuperación de la } \\
\text { dignidad, la transformación } \\
\text { emocional y la } \\
\text { reconstrucción del tejido } \\
\text { social. (Rehabilitación) }\end{array}$ & $\begin{array}{l}\text { 1. Procesos de apoyo } \\
\text { mutuo, en algunos casos } \\
\text { dirigidos y coordinados en } \\
\text { el marco de un proyecto de } \\
\text { intervención, que } \\
\text { promueven la } \\
\text { dignificación, el } \\
\text { empoderamiento, la } \\
\text { recuperación emocional y } \\
\text { la reconstrucción del tejido } \\
\text { social. } \\
\text { (Rehabilitación desde } \\
\text { abajo) }\end{array}$ & $\begin{array}{l}\text { 1. Intervenciones } \\
\text { paliativas, centradas o bien, } \\
\text { en maquillar la acción del } \\
\text { Estado, o bien asumir el } \\
\text { trabajo sobre síntomas } \\
\text { psíquicos, sin que implique } \\
\text { transformaciones } \\
\text { subjetivas profundas. Las } \\
\text { víctimas lo sienten como } \\
\text { "paños de agua tibia": No } \\
\text { hay rehabilitación. }\end{array}$ \\
\hline $\begin{array}{l}\text { 2. El empoderamiento de } \\
\text { los sujetos se ve } \\
\text { acompañado de medidas de } \\
\text { restitución, indemnización. }\end{array}$ & $\begin{array}{l}\text { 2. El empoderamiento de } \\
\text { los sujetos surge de los } \\
\text { procesos de acción pública } \\
\text { y el afrontamiento y la } \\
\text { resistencia que se genera } \\
\text { para poder luchar por los } \\
\text { derechos. }\end{array}$ & $\begin{array}{l}\text { 2. No genera } \\
\text { empoderamiento de los } \\
\text { sujetos, genera } \\
\text { dependencia, una mirada } \\
\text { miserabilista, que asume } \\
\text { actitudes fatalistas y de } \\
\text { subyugación frente al } \\
\text { poder. "se piden ayudas, } \\
\text { se recibe limosna" }\end{array}$ \\
\hline $\begin{array}{l}\text { 3. Una acción } \\
\text { dignificadora donde los } \\
\text { sujetos aumentan su } \\
\text { autoestima, su valoración } \\
\text { de sí mismos y recuperan } \\
\text { el control sobre sus propias } \\
\text { vidas. Se logra la simetría } \\
\text { de las víctimas frente a los } \\
\text { poderes establecidos y los } \\
\text { victimarios. }\end{array}$ & $\begin{array}{l}\text { 3. Se logra dignificar a los } \\
\text { sujetos que se sienten } \\
\text { partícipes de su propia } \\
\text { historia. Pero, se mantienen } \\
\text { situaciones de dominación } \\
\text { y explotación por parte de } \\
\text { poderes tradicionales y los } \\
\text { victimarios. Con este tipo } \\
\text { de acciones, las víctimas } \\
\text { no logran transformar la } \\
\text { realidad de opresión y } \\
\text { exclusión, más allá de } \\
\text { enunciarla y denunciarla. }\end{array}$ & $\begin{array}{l}\text { 3. No dignifica. La gente } \\
\text { siente que hace una } \\
\text { transacción para suplir } \\
\text { necesidades básicas, pero } \\
\text { al costo de la propia } \\
\text { dignidad y la de las } \\
\text { víctimas. Tiene costos } \\
\text { emocionales, morales y } \\
\text { comportamentales altos, } \\
\text { aún cuando se reconoce } \\
\text { que era una obligación del } \\
\text { Estado y que el dinero era } \\
\text { necesario. }\end{array}$ \\
\hline
\end{tabular}




\begin{tabular}{|c|c|c|}
\hline $\begin{array}{l}\text { 4. Solamente es posible en } \\
\text { marcos de verdad y } \\
\text { justicia. Puesto que } \\
\text { garantiza la no repetición. }\end{array}$ & $\begin{array}{l}\text { 4. Es una respuesta de la } \\
\text { gente, en un marco de } \\
\text { sociedad civil, a contextos } \\
\text { de injusticia, impunidad, } \\
\text { ausencia de verdad. Es una } \\
\text { forma de enunciación } \\
\text { alternativa que puede, si } \\
\text { hay un proceso exitoso, } \\
\text { confrontar la historia } \\
\text { oficial. }\end{array}$ & $\begin{array}{l}\text { 4. Puede mantenerse la } \\
\text { Impunidad. Con la } \\
\text { reparación se puede } \\
\text { generar una transacción a } \\
\text { cambio del silencio de la } \\
\text { gente, disminuir la presión } \\
\text { de la sociedad civil y los } \\
\text { movimientos de víctimas } \\
\text { sobre el Estado y la } \\
\text { confrontación a la historia } \\
\text { oficial. }\end{array}$ \\
\hline $\begin{array}{l}\text { 5. Hay garantías para las } \\
\text { acciones públicas de la } \\
\text { gente desde abajo. Es } \\
\text { decir, incluye los procesos } \\
\text { locales y desde abajo, y se } \\
\text { plantea las acciones de } \\
\text { reparación según los } \\
\text { contextos, las culturas y las } \\
\text { situaciones particulares. }\end{array}$ & $\begin{array}{l}\text { 2. No tiene garantías para } \\
\text { realizarse. En algunos } \\
\text { contextos (Córdoba o en } \\
\text { procesos de elecciones, } \\
\text { como en 2011) se ven } \\
\text { amenazadas y se reducen } \\
\text { en su posibilidad de } \\
\text { impacto, deben bajar el } \\
\text { perfil. }\end{array}$ & $\begin{array}{l}\text { 5. Se trata de una fórmula } \\
\text { para todo el mundo, sin } \\
\text { contextualización, sin una } \\
\text { visión de la gente, sin una } \\
\text { sensibilización y sin } \\
\text { reconocimiento del dolor y } \\
\text { la dignidad de la gente. No } \\
\text { importan los contextos de } \\
\text { seguridad. Todo sigue } \\
\text { igual, pero se "paga" un } \\
\text { dinero con el que se } \\
\text { pretende "compensar" el } \\
\text { mal infligido o no } \\
\text { protegido. }\end{array}$ \\
\hline $\begin{array}{l}\text { 6. Fortalece los sujetos } \\
\text { individuales y colectivos. } \\
\text { Realmente se constituye en } \\
\text { una acción reparadora. }\end{array}$ & $\begin{array}{l}\text { 6. Fortalece hasta ciertos } \\
\text { límites (contextuales y de } \\
\text { seguridad) a los sujetos } \\
\text { individuales y colectivos. } \\
\text { Interacción continua entre } \\
\text { amenaza, vulnerabilidad y } \\
\text { resistencia. Por lo tanto, } \\
\text { tiene límites en su acción } \\
\text { reparadora. }\end{array}$ & $\begin{array}{l}\text { 6. No repara. Puede } \\
\text { revictimizar. }\end{array}$ \\
\hline $\begin{array}{l}\text { 7. Se favorece una } \\
\text { integración entre las } \\
\text { formas de memoria } \\
\text { performativa y las formas } \\
\text { documentales que permitan } \\
\text { la construcción de una } \\
\text { memoria histórica. Implica } \\
\text { medidas de satisfacción. }\end{array}$ & $\begin{array}{l}\text { 7. Priman las formas de la } \\
\text { memoria performativa, lo } \\
\text { que puede tener el riesgo } \\
\text { de construir una memoria } \\
\text { mítica en torno a la } \\
\text { violencia. Hay unos } \\
\text { escenarios que reparan y } \\
\text { dan satisfacción, más por la } \\
\text { capacidad de la gente de } \\
\text { resistir y dignificarse, que } \\
\text { por la garantía de un } \\
\text { derecho. }\end{array}$ & $\begin{array}{l}\text { 7. Se intenta hacer } \\
\text { memoria, más desde } \\
\text { investigaciones académicas } \\
\text { y documentando las } \\
\text { experiencias populares, hay } \\
\text { una memoria documento y } \\
\text { también se han apoyado } \\
\text { algunos casos de memoria } \\
\text { performativa. Pero una } \\
\text { memoria sin comisión de la } \\
\text { verdad, y con una } \\
\text { reparación incompleta, } \\
\text { puede llegar a ser una } \\
\text { constatación cínica de } \\
\text { hechos o una producción } \\
\text { intelectual que no cala en } \\
\text { la sociedad. No es una } \\
\text { medida de satisfacción. }\end{array}$ \\
\hline
\end{tabular}

Tabla1: Fuente propia 
"Hemos sabido algo de la verdad, pero a medias": Versiones libres sin verdad

El contexto que se ha tejido en Colombia, aparenta una situación transicional, entre el conflicto armado y la consolidación de una democracia. De alli que se hayan constituido leyes de "justicia transicional". Estas leyes aparentan hacer énfasis en la reparación de las víctimas, y en ofrecer justicia alternativa (penas de 8 años para los exparamilitares y guerrilleros desmovilizados) a cambio de contar la verdad de sus delitos en versiones libres que son adelantadas por la fiscalía general de la nación. El país lleva 6 años de versiones libres de comandantes paramilitares y muy pocas sentencias (Forer, 2011). Fue claro que la extradición de los principales comandantes paramilitares a los Estados Unidos para ser procesados por narcotráfico respondió a una estrategia para que en sus versiones libres no siguieran implicando a miembros de élites gubernamentales, regionales y empresariales, lo cual hubiera representado una parte de la verdad sobre el conflicto armado en Colombia, especialmente, sobre la forma como se constituyó el proyecto paramilitar y quienes estaban detrás de esta máquina de muerte $y$, por lo tanto, fueron sus principales beneficiados.

De otro lado, prestigiosos investigadores y académicos han afirmado en múltiples ocasiones que la verdad debe ser principalmente, la verdad desde las víctimas. Más claramente, que la verdad debe empezar por abrir escenarios para escuchar, dar lugar al relato de las víctimas, de tal manera que se convierta en un espacio de dignificación y reconocimiento social para ellos y ellas (Hayner, 2008, b; Martín Beristain, 2007, 2008, 2010; Lira, 1999, 2007; Hamber, 1997, 1998, 2000; López, 2003, entre otros). Pero Colombia aún está lejos de escenarios de verdad y de la constitución de una comisión de la verdad. Por lo tanto, al parecer la verdad es un anhelo de las víctimas, no satisfecho y denegado sistemáticamente en el único escenario oficial para ello: las versiones libres de los paramilitares.

Como anhelo la verdad significa un alivio para los y las participantes en esta investigación, un consuelo ante su permanente reclamo por saber qué pasó y por qué pasó, ya que para la mayoría sigue siendo incomprensible la violencia padecida. La verdad es un apoyo dentro del proceso de transformación subjetiva, porque podría permitir darle algún sentido a lo ocurrido, de alli que sea tan importante para los y las participantes:

...yo creo que una solución es que se sepa lo de mi hija, que a lo menos que se busque la verdad, que se sepa la verdad, o que las personas que lo hicieron digan por qué lo hicieron y dónde está, si es que existen... (Oriente, E28)

Por esta razón muchos y muchas han querido acceder a algunos de los mecanismos que posibilitaría la ley. Sin embargo la verdad que han obtenido, es una verdad a cuentagotas y una verdad a medias, manejada y manipulada según los intereses del victimario, amañada según las circunstancias, con muy pocas posibilidades de ser confrontada por la investigación judicial, puesto que la estructura de las versiones libres está diseñada para dar todas las garantías al victimario y muy pocas a las víctimas:

...hemos sabido algo de la verdad, pero a medias porque hay cosas que nosotros sabemos que él no nos dijo y saber que por ejemplo había alguien que conocíamos implicado, que nos hayamos sentido satisfechas por un lado y por el otro no... Porque él nos dijo la verdad a medias y no estamos satisfechas por eso, porque el que nos dio la versión, no nos ha dicho toda la verdad... (Oriente, E16) 
Sin embargo, para algunas personas, especialmente familiares de desaparecidos ha significado una respuesta al paradero de sus seres queridos, con lo cual empiezan a hacer el cierre de sus largos procesos de duelo, logrando una respuesta y por lo menos empezar a descansar de la eterna espera. En efecto algunas mujeres, especialmente de Madres de la Candelaria han logrado saber dónde están sus hijos enterrados, hacer las pruebas de ADN y han recibido los restos de sus hijos y, por lo menos, han cerrado la agonía permanente de esperar.

Esta es quizás la única verdad que han recibido: las razones, los autores reales, los intelectuales, los vínculos con los actores de poder, los responsables, se quedan en el silencio y en el olvido. De esta manera, según Uribe (2010) se reedita una nueva versión de la memoria mítica colombiana (Pécaut, 2003). Puesto que al final el discurso es el mismo: "todo fue culpa de la violencia". Las madres descansan con los restos, y es un descanso después de años sin saber apenas nada; pero este descanso tiene el precio del olvido y la impunidad:

...para mí son afortunadas las madres que tienen la oportunidad de volver a ver a su hijo, así sea en un cajón como nos ha tocado ver que llegan 15 o 20 cajoncitos con los huesitos y ver a una pobre madre llorando sin saber ella qué hacer, eso también es otro proceso muy doloroso y eso es algo que me ha dado muy duro, de yo saber de que ya simplemente llegaron los huesitos, y ver a una pobre madre ahí acariciando un cajón, llorando unos huesos... de todas formas, es bueno para la madre porque ya tiene la fortuna de que tiene a ese ser querido y va a poder empezar a elaborar un duelo; pero muy duro también, porque eso no es justo, o sea, no es justo de que una pobre madre después de pasar tanto dolor y tener la esperanza de que su hijo va a regresar vivo como lo repite en la consigna: "vivo, libre y en paz"; y encontrarse con él muerto, en huesitos, y fuera de eso en un cajón y encontrarlo en la manera como lo encuentran, ya enterrado peor que un perro, porque llegar y enterrarlo y tirarle encima 20 en una fosa común, eso es para mí muy triste, eso me parte el alma... (Madres, E5)

Queda esa tristeza, queda ese sinsabor. Ahora bien, las familias de los desaparecidos hacen lo que sea para, por lo menos, acceder a esta verdad que dé descanso ante la incertidumbre permanente y la angustia y zozobra que genera, buscan y buscan hasta encontrar esa verdad. Pero como se trata de verdades a medias. En muchas ocasiones, esa búsqueda es infructuosa, puesto que está sometida a la "buena" voluntad, a los intereses judiciales, a los cálculos políticos o personales de los victimarios. Así pues, cuando conviene dan razón de los desaparecidos, dan información sobre hechos y fosas comunes. Pero cuando no conviene, guardan silencio, no aportan datos y les importa muy poco el dolor de las víctimas:

...yo pienso que ellos lo mejor que pudieran hacer es decir la verdad para afrontar lo que ellos hicieron y reconocer el error que cometieron, y primeramente darle el descanso a esas madres que están esperando que sus hijos vuelvan; que muchos de los paramilitares en versiones libres van entregando esa verdad a cuentagotas, recordando lentamente y ponen a las víctimas como un muñeco... y para mí eso es injusto, porque llegan y les dicen: "usted mato 200, tranquilo que son ocho años de cárcel y usted va y eso lo paga en un momentico"; y ellos: "no, lo que pasa es que yo tengo amnesia, pero si me tratan bien voy recordando; entre mejor me traten y más beneficios me vayan dando, más voy recordando". Y así, en ese jueguito es que nos tienen... (Madres, E5)

De esta forma muchas víctimas se quedan sin esa porción de verdad, o la información es falseada, o simplemente se han borrado los rastros, o se han sacado los cuerpos y se han "desaparecido nuevamente". Por lo tanto, ni verdad, ni alivio ni consuelo para la gran mayoría 
de las personas. En una experiencia que mantiene lo fundamental oculto: los responsables, los hechos, los motivos, y la voz de las víctimas. Por esta razón la participación en las audiencias para la versión libre de los comandantes, tampoco ha contribuido a fomentar el efecto reparador que ésta tendría en las víctimas:

...cuando las cosas no son con ese propósito, de que cometieron una falta y la van a reparar, va uno a los hechos y se siente engañado, se siente muy mal, se siente re-victimizado, se siente más víctima, se siente más señalado, se va coartando, entonces, eso le hace mucho daño a uno... va creando a uno esa atmósfera de impedimento, de impotencia, va creando más rencor, mas resentimiento, hacia esa persona que lo victimizó... uno siente que lo están manoseando, que lo están manipulando, sin encontrar uno el favor de ellos, de ir entregando verdades, aunque sea de a poquito, pero que lo que entregue sea verdad... y eso muchas veces no se da. (Madres, E4)

Es inevitable hacerse la pregunta: ¿'entonces por qué siguen insistiendo en participar en estos espacios, a pesar que muchas veces pasa eso, que se sienten revictimizados, que se sienten maltratados? Es complejo intentar comprender y explicar ¿qué los mueve a seguir ahí en esas sesiones de justicia y paz, cuando no contribuyen a las dinámicas de recuperación emocional, empoderamiento y redignificación de las víctimas?

...en mi caso es que lo que se me perdió a mí es un valor, a mí se me perdió una persona que me llenó de alegría, me llenó de superación, y de un momento a otro me lo quitan... en encontrar, en el caso mío, esos restos que le hablen a uno y que le digan: "Darío muchas gracias... fuiste leal conmigo" (llanto)... (Madres, E4)

Por el contrario, hay un efecto revictimizador, un efecto de aumentar la rabia, el desconsuelo, la angustia. Para quienes pretenden generar reconciliación a través de este tipo de mecanismos, la realidad parece ir mostrando el efecto contrario. Varios de los y las participantes en esta investigación que han participado de las versiones libres, afirmaron haber aumentado sus niveles de rabia, resentimiento, dolor, angustia y deseos de venganza. Y esto también es válido en las versiones libres que se han abierto para desmovilizados de la guerrilla de las FARC, puesto que el sistema y el comportamiento del victimario son similares:

...yo estuve en varias versiones libres, yo no quiero ser como hipócrita pero te digo que uno siente mucha rabia, de ver que ellos son tan falsos, y tratan como de evadir y de contar lo que a ellos les conviene... La motivación fundamental para participar en eso fue para averiguar por el hijo mío... (Madres, E8). .... nosotras nos llevaron una vez a unas versiones libres en la cárcel de Bellavista con los guerrilleros, supuestamente llevé la foto y uno me dijo que lo iban a averiguar, pero hasta el son de hoy... no averiguaron nada... nos tienen a las víctimas, como jugando porque esa gente no quiere contar la verdad.... (Madres, E3)

Como puede observarse, no existe un marco para la contención, no existe un escenario que compela a la verdad, no se reconocen los hechos, ni mucho menos las responsabilidades. Se trata nuevamente de otro acto "caritativo", ahora de parte del victimario, acompañado por funcionarios del Estado que, bajo una pretendida generosidad le "ofrecen" información a las víctimas sobre el paradero de sus seres queridos, al precio de tener informaciones parciales, de jugar con el dolor de la gente, de tener que enrostrar el cinismo de los actores de violencia.

Por lo tanto y a manera de síntesis, en este contexto, la verdad no está cumpliendo un papel reparador. Ni siquiera se puede asumir la discusión que plantean Hamber $(2002,2011)$, 
Laplante \& Theidon (2006), Castillejo (2007), Gibson (2005), entre otros, sobre la relación entre verdad y sanación emocional en el marco de las comisiones de la verdad, porque en el contexto colombiano no ha sido posible este marco y no parece posible en el inmediato futuro. Hasta ahora, los escenarios de verdad han sido los de la memoria, tanto los de la memoria performativa, en las múltiples experiencias referenciadas por María Victoria Uribe (2010) y el Centro de Memoria Histórica, las presentadas en mi tesis doctoral (Cfr. Villa, 2012) y las acciones de memoria documento de organizaciones de la sociedad civil en proyectos como Colombia Nunca Más y el Movimiento de Víctimas de Estado (MOVICE).

Intentando hacer justicia en contextos de impunidad:

De entrada, puede afirmarse con Sikkink y Booth-Walling (2007) que la justicia tiene un papel regulador en el marco de construcción de la sociedad y el Estado, que posibilita el fortalecimiento de los marcos legales, la rendición de cuentas de los actores políticos y armados, la responsabilización por los hechos de violencia. Además abre un marco social que invita al respeto de los derechos humanos, que contribuye a la garantía para que no se repitan los hechos violentos.

La justicia y la verdad judicial, al lado de la verdad histórica (Martín Beristain, 2008, 2010), permiten el paso de las construcciones de memoria pública y memoria colectiva a la construcción de una memoria histórica; puesto que los hechos quedan fijados, reconocidos y sancionados de forma oficial, lo que se corrobora con la sanción a los responsables.

En el contexto de esta investigación aparecen algunas acciones esporádicas e individuales, en los relatos de vida de los y las participantes: 8 personas de 62 (cerca del 14\%) que han desarrollado algún tipo de acción jurídica: denuncia, participación en un juicio, indagatoria, ser testigo o tener una sentencia judicial que sancionó a sus agresores. La cifra en términos del deber ser es muy baja; pero en términos del contexto y del proceso de las personas que han participado en esta investigación, tal como se ha enunciado en los capítulos precedentes y a lo largo de este capítulo, es algo significativo y sorprendente.

Es claro que hay procesos de víctimas en Colombia como el Movimiento de Víctimas de Estado (MOVICE) que le ha dado un lugar primordial a la justicia y ha intentado utilizar todas las posibilidades al respecto, desde apelar a la justicia ordinaria, hasta buscar justicia a través de la corte interamericana de derechos humanos y la corte penal internacional; pero en los colectivos estudiados y en los contextos donde viven, este tipo de procesos ha sido mucho más limitado, y aunque tengan una vinculación más individual que colectiva; donde se implica la familia, más que la organización, no se debe dejar de mencionar que buena parte de estas acciones en búsqueda de la justicia han sido una opción razonable para las personas, luego de haber participado en todo el proceso de memoria colectiva y organización de víctimas:

...me siento como que estoy tratando de hacer justicia, como una satisfacción porque estoy diciendo la verdad, que nadie me ha escuchado, entonces quiero que me escuchen, que esto se conozca, que no quede así en la simple impunidad, que no quede a oscuras, como se dice... interiormente y moralmente me siento mejor, porque siento que estoy cumpliendo con una obligación que tengo, porque yo soy el único encargado de mi familia, de que esto no se quede quieto, no se quede en la impunidad; en mi familia nadie más quiere, inclusive me han dicho que me esté callado, que puede ser peligroso, que casi ni les gusta que yo dé estos testimonios, pero yo los doy porque siento como una obligación... (Oriente, E3) 
Ya María Luisa Cabrera (2001, 2008), en el contexto guatemalteco, encontró que, a pesar del contexto de impunidad, violencia y amenaza vital, la gente ve en estos procesos un escenario para la reivindicación moral de la dignidad de las víctimas, y una forma de lucha y resistencia para tener un mejor futuro, y para reconstruir la convivencia social. Muchas veces se hace al costo de la propia seguridad, pero sintiendo que de una u otra forma se está logrando restablecer un equilibrio:

...y que por fin logré que se descubriera quién hizo la masacre, logré descubrir al que hizo la masacre, porque boté el miedo y lo denuncié y ya está en Bellavista (la cárcel de Medellín), que siento miedo sí, pero lo logré.... Ese proceso yo vine a echarlo al aire hace tres años más o menos y ya estaba para prescribir... y hace por lo menos 3 meses que lo capturaron, fue el autor principal de la masacre; habia que hacer justicia, las cosas no se podian quedar en la impunidad... (Madres, E1)

De otro lado, Martín Beristain, Páez, Rimé y Kanyangara (2010) en un estudio en Guatemala, Sudáfrica y Ruanda afirman que la búsqueda de la justicia y la participación en estos escenarios promueve una mayor cohesión social, empoderamiento social y actitudes de resistencia y lucha, aunque emocionalmente pueden generar un mayor malestar: tristeza, rabia, resentimiento y dolor. Sin embargo, para estos autores y para los y las participantes que han desarrollado procesos de justicia, puede resultar una experiencia que aumenta su capacidad de afrontamiento y sus posibilidades de lucha:

...satisfechas porque los fiscales actuaron y mostraron que había alguien que fue el que mató a mi hermano, entonces ya nos sentimos satisfechas porque a él ya lo cogieron, ya han cogido a varios de los que tuvieron que ver con la muerte de mi hermano, entonces se siente uno que la justicia si va actuando... (Oriente, E16)

Ahora bien, uno de los riesgos de participar en estos escenarios en contextos de impunidad, como el colombiano, está en que pueden ser espacios donde los abogados (los de la contraparte) intentan por todos los medios demostrar que la víctima no tiene ningún derecho, que miente, se contradice, para poder favorecer a su cliente. Así pues, el escenario judicial puede ser sumamente hostil para las víctimas; ya que se hará lo posible por desacreditar un testimonio que ha sido acogido en otros escenarios, o que en una comisión de la verdad sería recibido de otra manera:

Referente a ese caso, hace, por lo menos, dos meses bajó la fiscalía, abajo al lugar donde ocurrieron los hechos, hicieron la inspección y todas las cuestiones, ese caso posiblemente lo perdemos, la muerte de la niña puede quedar impune. La única testigo era la otra niña que estaba con ella, cuando bajó la fiscalía, bajaron los soldados que hicieron ese daño, bajó el abogado de ellos, bajó el abogado de nosotros también... la niña bajó y se perturbó toda, se puso a llorar, como que no habló en forma, tuvo ciertas fallas en relación con las declaraciones que había dado... ellos la enredaron por la astucia que tienen, como ya saben de leyes, ellos se supieron defender muy bien, con mentiras sí, y el abogado de ellos es un señor, con todo respeto, con mucha astucia, que es muy especial en ganarle casos al ejército, entonces debido a eso vemos malo, que de pronto ese caso lo perdemos nosotros, o sea que nos vamos a quedar así, todo lo perdimos: perdimos la hija, perdimos el trabajo de toda la vida mío, y no sé en qué irá a parar todo esto... (Oriente, E3)

Y este escenario del "careo" judicial puede aumentar los niveles de indefensión y la sensación de injusticia de la víctima, porque experimenta que su experiencia no solamente es 
desmentida, sino además tergiversada, al punto que el victimario puede terminar en el lugar de la víctima. También se convierten en escenarios de revictimización cuando los procesos se alargan en el tiempo, cuando el testimonio de la víctima es tomado una y otra vez, lo cual genera agobio y malestar emocional fuerte, puesto que es un recuerdo sin sentido y sin un fin claro, ya que se busca más la contradicción, la caída en inconsistencias del testigo, que afirmarle en su verdad y protegerle en sus derechos; $y$ al final tampoco hay resultados, porque pareciera que la justicia termina poniéndose del lado del victimario. Así pues, el proceso judicial parece más un túnel en el que se entra pero no se sale jamás, generando un desgaste que parece nunca va a terminar. Y al final, pareciera que todo queda igual:

...el Estado, por ejemplo, en el caso de nosotros, de mi hermano lleva un proceso que ya lleva 14 años va a cumplir 15, y qué pasa con mi hermana, que todavía es la hora que mi hermana no deja de declarar, cuando a ellos les da la gana, tiene que ir mi hermana a declarar lo mismo de siempre... eso termina haciéndole daño a uno, porque recordar, recordar y recordar algo... un episodio malo... Cuando tú estás recordando en un abrazo (grupo de apoyo mutuo) o en un acto de memoria lo haces naturalmente, lo haces calmadamente, mientras que con el gobierno no, porque con el gobierno tú puedes ser el fiscal y me vas haciendo preguntas, pero yo no sé si tú estás del lado de los criminales, y no me atrevo a soltar todo el rollo como es; porque cuántas personas han ido a declarar y después las han matado, porque han dicho la gente que mató a su familiar, entonces no hay confianza... ¡Es tan duro entrar en confianza con la fiscalía!... (Córdoba, E1)

En muchos casos esta forma de la memoria termina siendo nociva porque el recuerdo no genera una resignificación, sino, por el contrario, es sometido incesantemente a una prueba y a otra para determinar su validez, para buscarle la contradicción. Si además se agrega la desconfianza en algunas instituciones del Estado, porque pueden estar cooptadas por los actores de poder y armados, el escenario es muy complejo, puede llevar a contradicciones, ocultar información, y otra serie de fallas que terminan por desvalorizar el testimonio de la víctima, que por tanto, deja de ser reparador y sanador, como en el siguiente relato:

...y yo se que a mí me llamaron hace días a declarar, a la fiscalía del batallón y era bastante miedo que tenía, por eso inclusive no dije toda la verdad, dije que algunas cosas, pero no dije lo del camión, no dije que esa gente estaba allá, o sea, yo debido al miedo que me daban los otros (paramilitares) no les conté la verdad, que es una cosa que me ha pesado mucho, no haber dicho como había sido, como habian matado la niña... Cuando la fui a ver que ni abotonada estaba, no tenía uniforme, yo estoy segura que no hubiera aparecido como un falso positivo... (Oriente, E28)

El miedo, el sentirse en un lugar adverso y hostil, la presión a la que es sometida la persona en el interrogatorio, puede llevar a estas fallas en la información que son utilizadas para deslegitimar su testimonio y darle cabida a la impunidad y a la ausencia de justicia. Y al final, incluso a la legitimación de los hechos. Esto construye un clima de impunidad global que termina generando parálisis, miedo a actuar, denunciar y proceder jurídicamente, anomia y retiro de lo público. O también en el caso de los colectivos estudiados, que la memoria colectiva y pública, se remita a una dimensión performativa y simbólica, mientras que la documentación de los hechos y los casos, o bien no se asume, o bien se asume de bajo perfil, en una perspectiva de archivo e histórica, más que en el marco de una lucha por la justicia. Al fin y al cabo en Colombia, la gente está acostumbrada a ver cómo quienes reclaman justicia, se convierten en nuevas víctimas. 
Así pues, estos escenarios pueden generar mayor desesperanza, aumentar el fatalismo y disminuir la creencia en el mundo como un lugar seguro, en las instituciones y restarle valor al sí mismo y a la vida misma. La resignación aparece como conducta más aconsejable y el retiro de cualquier acción política o jurídica aparece como lo más recomendable. Es en estos contextos donde el perdón termina siendo asumido por las víctimas como su única opción, una imposición por contraste, es decir: como no hay nada que hacer, la lucha es infructuosa, por lo menos quitarse el peso de encima:

Entonces yo fui y por ahí derecho hice mis declaraciones, dije todo, demandé a esa gente de una vez con abogado y con todo, yo hice la demanda contra el Estado entonces empezaron las llamadas, las boletas, las razones, entonces, yo me volvi para Santo Domingo el barrio de toda la vida, y allá intentaron llevárseme otro hijo que tiene 19 años, intentaron llevárselo dos veces... no le encuentro como remedio a eso, porque paz no va a haber nunca, ¿usted cree en la paz o cree que va a haber paz algún día? De pronto, la paz la puede tener uno interiormente, perdonando, pero que haya paz en este mundo, que van a dejar de matar, que van a dejar de violar, que van a dejar de secuestrar, que van a dejar de desaparecer, esto que ocurre todos los días, eso no creo que vaya a dejar de pasar... (Madres, E7)

Por lo tanto, aunque se quiere hacer, aunque la movilización se organiza para poder llegar algún día a ese punto, en la realidad, la gente asume que es peligroso y que el margen de acción es limitado, por lo que se experimenta indefensión, soledad, ausencia de sentido, impotencia, y las acciones para reivindicar los derechos son mínimas. Hay un aprendizaje histórico, en el cual se observa que el ejercicio de una ciudadanía plena de derechos puede ser peligrosa, de alli que mucha gente se adapte a estas circunstancias:

...me siento indefensa, como sin ayuda de nadie. Ni del gobierno ni de nada. No he denunciado porque me da miedo. Como vinieron a decirme que no fuera a denunciar... entonces ese temor yo... tengo todavía eso... una vez fui, me saqué un papel para denunciar, y yo no fui... Acordándome de que me amenazaron que cuidado iba y denunciaba, entonces yo no denuncié nada. (Córdoba, E3)

Y sin embargo, algunos y algunas han dado el paso, como se documenta en esta investigación. Cabrera (2001, 2004, 2008), Gibson (2005), Martín Beristain (2006, 2007a, 2007b, 2008; Lykes, Martín Beristain y Cabrera (2007); Martín Beristain, et. al. (2010) se hacen la pregunta por las razones que tienen los sujetos para participar en estos espacios de justicia, aún en contextos de violencia e impunidad. Y se responden que a pesar de los efectos negativos, los costos emocionales, los riesgos que se asumen y la sensación de injusticia que se puede generar al final, se experimenta la fuerza de estar luchando contra algo más fuerte, la afirmación del propio ser, la generación de cohesión social cuando se hace de forma grupal, la experiencia de resistir a un poder, lo cual aumenta el empoderamiento personal y la autoestima. Por eso algunas personas asumen riesgos, son conscientes de los costos que puede tener, y se preparan para "dar la batalla":

...yo denuncié en el 2007, entonces desde que denuncié ya empezaron los testigos, que una cosa, que otra, entonces yo les colaboraba y decía aquí está el testigo, ellos venían a mi casa y ya fuimos recogiendo los testigos, entonces ellos empezaron a investigar todo, ya ellos me llamaban desde Medellín me decian: "X. vamos tal y tal día, necesitamos que nos recoja tantos testigos, esto y esto para que nos los tenga listos", bueno... ahí mismo yo arrancaba y les conseguía los testigos y vea que en realidad hemos avanzado mucho, porque ya van tres 
condenados, y poquito a poquito se van recogiendo todos, si Dios quiere, yo tengo fe de que los vayan cogiendo a todos... yo mantengo miedo porque de pronto mi niños quedan solos, ya han cogido tres, detienen a tres en la cárcel y falta uno, eso es todo... (Oriente, E26)

Se desarrolla una capacidad ética en la persona, puesto que logra trascender su propia experiencia personal y empieza a pensar en términos colectivos, comprendiendo que al final la impunidad podría vencerse si se lograra vencer el miedo, y juntar esfuerzos para afrontar la injusticia. Por eso, cuando se hablaba de formas de afrontamiento se mencionaba que una de ellas, podría implicar incluso asumir el papel de investigadores, con tal de mover la justicia y lograr romper con la impunidad:

...Me he convertido en una investigadora de la verdad... es que eso lo hace uno, eso lo hacemos las víctimas, y todavía sigo averiguando y todavia no me he quedado quieta, yo sigo, yo sigo averiguando hasta que encuentre... (Madres, E2)

Giraldo (2009) apunta que la situación de impunidad en Colombia es estructural. Por lo tanto, el sistema parece claramente hecho para favorecer a los victimarios, mucho más cuando quienes administran justicia están ligados a las élites en el poder. Así pues, en un contexto donde el Estado se pone al servicio de estas élites, la justicia termina siendo parcial e incapaz de abrir posibilidades para la sanción de los responsables.

De otro lado, escenarios de esta naturaleza, han llevado a que muchos autores se pregunten por su conveniencia, tanto en procesos judiciales ordinarios, como en escenarios de justicia transicional. Puesto que al tener poder revictimizador, podrian ser sustituidos por otro tipo de acciones. Así pues, Naraghi, Conway y Kays (2005 a, b) dan cuenta precisamente de las dificultades, limites y defectos de este escenario de justicia:

- Los procesamientos se concentran principalmente en el perpetrador y no en la víctima, que generalmente no recibe la atención necesaria.

- Los juicios pueden dar lugar a nuevas formas de victimización, porque las personas son sometidas a interrogatorios extensos, potencialmente hostiles y humillantes.

- Se puede limitar la información, lo cual dificulta procesos de verdad. La confesión del perpetrador se hace más difícil. No se investigan las estructuras sistémicas e institucionales que permitieron o contribuyeron a la comisión de los delitos. Lo cual genera inequidad, porque de acuerdo con Huyse (2003) quienes terminan castigados no son los principales perpetradores.

- En definitiva se puede bloquear un proceso de reconstrucción de tejido social puesto que las víctimas pueden no asumir su papel en la reconstitución de sus vidas y del vínculo social (Cfr. Villa, et. al, 2007).

Sin embargo, para otros como Cabrera (2004) o Martín Beristain (2007a, 2008) no se puede renunciar a la justicia, porque a través de ella la gente resiste a este sistema y lo hace desde el compartir social, la reevaluación positiva de los hechos, la lucha por la verdad, la memoria y la justicia. De allí que la participación en juicios sin justicia, aunque no sirvan para hacer justicia, sí tienen repercusiones positivas en el ámbito de la reparación psicosocial individual y colectiva: 
...a mí me ayudó a elaborar el duelo cuando yo me atreví a denunciar los hechos que habían pasado... Me generó una confianza en mí misma, en mis hijos, en mi familia y en todo, eso lo que me genera a mí, y también otra cosa que me gustaria: que la gente de esta asociación se decidiera a denunciar y que todos habláramos, y que todos dijéramos: no más, no más silencio, aquí se acabó este silencio, vamos es a hablar... y me daría más felicidad de ver eso... (Oriente, E26)

De tal manera que se puede percibir que lograr algún nivel de justicia en un contexto de impunidad, es además complementario del proceso de recuperación emocional, de recuperación de la dignidad que se ha vivido en las acciones de memoria compartida, apoyo mutuo y memoria pública:

...a mí me ayudó a sanar fueron los abrazos (grupos de apoyo mutuo); claro que todo va conjunto, porque si yo hubiera sanado con los abrazos y no pudiera saber cómo mataron a mi hermano y tener este proceso, también sería muy triste; entonces eso también es beneficioso, porque todo permite que sepamos la verdad, entonces eso es satisfactorio para nosotros, porque si tuviera los abrazos y no supiera todavía, estaría todavía con la ansiedad de quién lo mató, quien fue y por qué. (Oriente, E16)

Uno de los problemas enunciados por algunos autores (Lederach, 1998; Galtung, 1999), es que en este marco de justicia, se realiza una escisión entre el nivel individual y el colectivo; de tal manera la dimensión subjetiva de las personas afectadas queda en manos de psicólogos y/o pastores religiosos, y se trabaja más en el ámbito de lo privado que de lo público; mientras la dimensión pública es asumida por juristas y políticos, sin que se promueva una mirada psicosocial "bisagra" entre estas dos dimensiones sistémicas que permitiría un trabajo integral en los procesos de recuperación emocional, reconstrucción de tejido social y estabilización política.

De todas formas, el juicio puede ser un medio para transformar en público el dolor que necesita ser complementado con escenarios dirigidos al nivel social, que se concretan en homenajes, construcción de monumentos, acciones públicas de desagravio, dignificación y reparación para reconocer y mitigar ese dolor; además del acompañamiento necesario a las víctimas en la elaboración de sus duelos y la transformación de sus emociones (Villa et al. 2007). Y en muchos casos, es el verdadero factor que puede promover el perdón y la reconciliación, puesto que disuade de la venganza y de la justicia por propia mano:

...porque déjeme decirle que yo esperaba que me llegara la reparación administrativa y cobrar venganza, usted no me va a creer que cuando a mí me llegó ese chichigua de reparación administrativa, a mí se me cambió la mente, pensé en mis hijos, en mi familia, no pensé en el victimario, yo dije: "yo voy con esa plata y me compro una pistola o una metra, y lo mandó matar"... Pero entonces fue la justicia la que me hizo cambiar, además he conocido tanta gente, que a pesar de ser de la justicia han sido buenos conmigo, muy buenos consejeros... (Madres, E1)

Este relato en su complejidad muestra nuevamente cómo la reparación administrativa sin justicia no logra la satisfacción, ni logra generar un clima para la transformación de la ecuación asimétrica en la relación víctima/victimario. De allí que aún con reparación económica, se siga analizando la posibilidad de la venganza y la perpetuación de la violencia. Al final es la justicia quien logra disuadir. De alli que no se deba renunciar a esta aspiración manifestada por las víctimas, sabiendo que esa lucha hace parte del proceso, aún cuando se esté lejos de lograr un escenario real de justicia en Colombia. 
De allí que quienes han asumido el riesgo de denunciar y entrar en un proceso judicial en búsqueda de la justicia, consideren que si ésta se llegara a dar, en su caso, la experiencia sería, además de positiva, restauradora, sanadora y con la capacidad de reconstruir el sentido vital, con una mayor aceptación del dolor y de la pérdida. Pero también la inversa, si se mantiene la impunidad, se aumentaría el resentimiento, el sentimiento de menosprecio de la vida humana y las posibilidades de venganza:

...si hubiera justicia, más tranquilos... no del todo, porque la pérdida de la niña es una cuestión que la tenemos y ya no puede remediarse, pero si hubiera justicia siempre cambiaría mucho, moral y espiritualmente sentiriamos una tranquilidad inmensa; pero que esto se quede impune como si nada hubiera sido, seguimos en las mismas (con lágrimas y tristeza): con la intranquilidad, el resentimiento, si esto se queda impune... esto quiere decir, que una vida no vale nada, el desprecio, el menosprecio por la vida, por los derechos humanos, a nosotros nos los violaron con lo que nos hicieron... que el gobierno nos preste atención, que nos repare lo que nos hicieron, que tiene obligación.... (Oriente, E3)

Ahora bien, no puede afirmarse tajantemente y de forma lineal que la justicia genere una recuperación emocional en las víctimas o que conduzca necesariamente a eliminar el odio o el resentimiento y dejar atrás el sentimiento de venganza (Simon, 2005). Tampoco lo contrario, que haya impunidad no quiere decir que se desarrolle el odio o el sentimiento de venganza. Sin embargo, según lo dicho hasta aquí, sí son factores que contribuyen a un mejor o peor estado emocional en el largo plazo. Y aún, cuando generan malestar emocional en el marco del proceso judicial (Cabrera, 2001, 2004, 2008; Martín Beristain, 2005, 2007; Gibson, 2005), a la larga al aumentar la cohesión social, la afirmación personal y colectiva y la resistencia, la autoestima y la valoración del sí mismo, redundarán también en un mejor pronóstico emocional. Por esta razón los y las participantes de esta investigación, cuando fueron interrogados sobre hipotéticos escenarios de justicia afirmaron que estarian mejor en su condición subjetiva:

E: ¿cómo cree usted que se sentiría si hubiera verdad, justicia y reparación?

A: pues prácticamente llega una luz al espíritu y a mi cuerpo... una luz, un regocijo, como si le volvieran el alma al cuerpo a uno, que se hizo justicia... (Oriente, E5).

Los procesos de memoria colectiva han sido muy importantes para los y las participantes, según lo que pude encontrar en mi trabajo de tesis doctoral (Cfr. Villa, 2012). La memoria compartida y el apoyo mutuo han sido muy significativos, especialmente en la dimensión emocional y en el abrir espacios de reconstrucción de los vínculos sociales. Se han desarrollado procesos que han abierto un camino, que aún no está terminado, hacia la ciudadanía. Sin embargo, los y las participantes reconocen que sin verdad ni justicia no puede haber una recuperación total, ni en lo individual ni en lo colectivo:

...digo que estoy bien en el $85 \%$, pero me falta el 15\% y lo voy a lograr el día que haya verdad, que haya justicia. Creo que uno de los victimarios es el mismo Estado, cuando mínimamente el Estado reconozca que ellos fueron culpables de la mayoría de las acciones que se han cometido en este país, creo que ahí habrá mucha parte de reparación y no se necesitaría tanta plata; creo que el solo hecho de que el Estado reconozca, el Estado nacional y local, porque son muchos los alcaldes, muchas las personas dentro del municipio que aportaron a esa guerra. Pero que haya reconocimiento, y que se pida perdón de verdad, realmente, públicamente, para las víctimas eso es muy importante, creo que eso sería más importante y 
más dignificante que los 20 millones de pesos; eso se acaba, pero ese reconocimiento y ese perdón público y que realmente se haga justicia... pero mientras tanto yo creo que va a ser dificil que lleguemos al 100\%. (Oriente, E20)

En el caso de los familiares de desaparecidos es fundamental que se cuente por lo menos con la verdad sobre el paradero de sus seres queridos, algo que en el actual contexto sigue siendo improbable. Por su parte, en el caso de los que fueron desplazados, también la parte económica, una reparación que incluya la restitución de la tierra y sus bienes será un aspecto fundamental para poder nombrarse a sí mismos como estando mejor, en términos anímicos y sociales.

Por tanto, recogiendo los relatos de los y las participantes, como también las investigaciones previas de otros autores en contextos similares, pueden definirse algunos factores positivos en la transformación subjetiva de las víctimas en lo individual y en lo colectivo, cuando se participa de un proceso judicial y cuando se logra justicia, junto con verdad y reparación. Pero también lo que pasa en la gente cuando se participa en el proceso y no se da un marco de justicia o cuando sencillamente hay impunidad. En la Tabla No. 2 puede observarse la sintesis de lo trabajado en este punto.

\begin{tabular}{|l|l|l|}
\hline \multicolumn{2}{|c|}{ Tabla No. 2 Consecuencias psicosociales de la participación en procesos judiciales en } \\
contextos de impunidad
\end{tabular}




\begin{tabular}{|c|c|c|}
\hline $\begin{array}{l}\text { Participación } \\
\text { en el proceso } \\
\text { judicial cuando } \\
\text { no hay justicia }\end{array}$ & $\begin{array}{l}\text { Corto plazo: } \\
\text { 1. Experiencia de fortaleza } \\
\text { interior, afrontamiento y } \\
\text { resistencia. } \\
\text { 2. Sensación de estar haciendo } \\
\text { algo. Protector frente a la } \\
\text { impotencia. } \\
\text { Largo Plazo: } \\
\text { 1. En procesos grupales la rabia } \\
\text { puede movilizar deseos de } \\
\text { resistencia y lucha. Aumentar } \\
\text { la cohesión social y dignificar } \\
\text { a las víctimas. }\end{array}$ & $\begin{array}{l}\text { Corto plazo: } \\
\text { 1. Sensación de injusticia, } \\
\text { impotencia, rabia. } \\
\text { 2. Sensación de indefensión y } \\
\text { desprotección. } \\
\text { 3. Aumenta el dolor, la rabia y el } \\
\text { resentimiento. } \\
\text { Largo plazo: } \\
\text { 1. Fatalismo. } \\
\text { 2. Anomia } \\
\text { 3. Retiro de lo público, } \\
\text { aislamiento. } \\
\text { 4. Resignación y desesperanza } \\
\text { aprendidas. } \\
\text { 5. Pérdida de confianza en } \\
\text { instituciones. } \\
\text { 6. No protege de los sentimientos } \\
\text { de venganza, deseo de hacer } \\
\text { justicia por propia mano. }\end{array}$ \\
\hline $\begin{array}{l}\text { No } \\
\text { participación } \\
\text { en procesos de } \\
\text { justicia pero } \\
\text { acciones de } \\
\text { memoria, } \\
\text { movilización } \\
\text { social en } \\
\text { búsqueda de la } \\
\text { "justicia } \\
\text { anamnética" }\end{array}$ & $\begin{array}{l}\text { Corto plazo: } \\
\text { 1. Dignificación de los seres } \\
\text { queridos, nombrando lo } \\
\text { innombrable. } \\
\text { 2. Afrontamiento y resistencia. } \\
\text { 3. Mejoría emocional parcial. } \\
\text { 4. Cohesión social, incremento } \\
\text { de la solidaridad. } \\
\text { 5. Ruptura de la anomia y el } \\
\text { aislamiento. } \\
\text { Largo plazo: } \\
\text { 1. Transformación subjetiva: } \\
\text { emocional, cognitiva y } \\
\text { comportamental. Con algunos } \\
\text { vacíos. } \\
\text { 2. Reconocimiento social y en } \\
\text { algunos casos reconocimiento } \\
\text { político de los hechos y las } \\
\text { víctimas. } \\
\text { 3. Empoderamiento y } \\
\text { construcción de un } \\
\text { movimiento social. } \\
\text { 4. Se ganan espacios para logros } \\
\text { parciales en verdad, justicia y } \\
\text { reparación. }\end{array}$ & $\begin{array}{l}\text { Largo plazo: } \\
\text { 1. Mantenimiento del Status Quo } \\
\text { 2. Anomia, retiro de lo público. } \\
\text { 3. Desconfianza en las vías } \\
\text { institucionales. } \\
\text { 4. No protege frente a } \\
\text { sentimientos de venganza. }\end{array}$ \\
\hline
\end{tabular}




\begin{tabular}{|c|c|c|}
\hline $\begin{array}{l}\text { No } \\
\text { participación } \\
\text { en procesos de } \\
\text { justicia / } \\
\text { aceptación de } \\
\text { la impunidad }\end{array}$ & $\begin{array}{l}\text { Corto plazo: } \\
\text { 1. Proteger la vida. } \\
\text { 2. Evitar situaciones difíciles, } \\
\text { dolorosas o que generen más } \\
\text { rabia e impotencia. } \\
\text { 3. Adaptación a la realidad, que } \\
\text { es más fuerte. } \\
\text { Largo Plazo: } \\
\text { 1. Adaptación a la realidad, que } \\
\text { es más fuerte. }\end{array}$ & $\begin{array}{l}\text { Corto plazo } \\
\text { 1. Sensación de injusticia, } \\
\text { impotencia, rabia. } \\
\text { 2. Sensación de desprotección. } \\
\text { 3. Aumenta el dolor, la rabia y el } \\
\text { resentimiento. } \\
\text { 4. No protege del temor ni del } \\
\text { miedo. } \\
\text { Largo plazo: } \\
\text { 1. Fatalismo. } \\
\text { 2. Anomia } \\
\text { 3. Retiro de lo público, } \\
\text { aislamiento. } \\
\text { 4. Resignación y desesperanza } \\
\text { aprendidas. } \\
\text { 5. Pérdida de confianza en } \\
\text { instituciones. } \\
\text { 6. No protege de los sentimientos } \\
\text { de venganza, deseo de hacer } \\
\text { justicia por propia mano. }\end{array}$ \\
\hline
\end{tabular}

\section{Conclusión.}

En América Latina, el nombre del olvido y la impunidad ha tenido el nombre del perdón, borrón y cuenta nueva, incluso el nombre de la reconciliación (Lira, 1998; Martín Beristain, 2000, 2006, 2008; Piper, 2005, 2009; Gaborit, 2006, etc.); por lo tanto, es importante para muchos determinar las consecuencias del olvido y la impunidad en las víctimas y en la sociedad. Ahora bien, en términos analíticos, sintomáticos y psicosociales, los efectos no difieren mucho de los enunciados anteriormente como efectos de la violencia política; puesto que las finalidades del olvido y la impunidad coinciden, tanto en los actores de la aplicación, como en los objetivos que se persiguen; por lo tanto, también lo harán en sus consecuencias psicosociales (Martín Beristain y Rieira, 1994; Piper, 2005, 2009). Esto tiene una explicación sencilla: "la impunidad representa la prolongación de la violencia en el presente, por el temor al uso de la fuerza como modo de contención de las demandas sociales" (Cabrera, 2004, P. 50), lo que produce un sentimiento de inermidad por la desvalorización de la vida y de la dignidad humana.

De otro lado, Lykes, Martín Beristain y Carbrera, (2007) afirman que las formas de afrontamiento y búsqueda de la justicia, pueden a largo plazo mejorar el clima emocional. Por tanto, ante las violaciones de derechos humanos, los procesos de intervención psicosocial que posibilitan la recuperación de la voz y la experiencia de las víctimas, rompiendo el silencio creado por el miedo y el horror, en el nivel microsocial, pueden generar cambios en la inhibición social, puede suscitar la movilización para la búsqueda de la justicia; y en el nivel mesosocial, pueden operar un cambio en la comunidad, en sus relaciones interpersonales. Esto finalmente genera espacios para la realización de una justicia que Reyes Mate (2006) denomina "anamnética"; es decir, aquella en la que la acción de la memoria y el testimonio de las víctimas es un referente ético, social y político para una colectividad, de tal manera que más allá del castigo, se ejecuta una sanción social, se tejen escenarios políticos de reparación y dignificación, y se reconoce desde todos los ámbitos la injusticia que implica la acción violenta. Desde allí, la voz de las víctimas y su participación en la vida pública de la nación serán referentes fundamentales sin los cuales no podría generarse una verdadera reconstrucción social, ni mucho menos un proceso de reconciliación nacional.

332 


\section{Referencias Bibliográficas.}

Bastidas, W., \& Insuasty Rodriguez, A. (2010). Víctimas en Medellín. El Agora USB. Vol 10 (2). Pag. 367-397.

Barkan, E. (2000). The Guilt of Nations. Norton, New York.

Cabrera, M. L. (2001). Efectos de la Impunidad en el sentido de la justicia. En: Revista de Psicología Política, No. 23, PP. 37 - 58.

Cabrera, M.L. (2004). Violencia e impunidad en comunidades mayas de Guatemala: La Masacre de Xamán. Tesis Doctoral Departamento de Antropología Social y Facultad de Ciencias Políticas y Sociología, Universidad Complutense de Madrid.

Cabrera, M. L. (2008). Memoria, identidad y justicia: desafios para la rehabilitación del tejido social. En: Revista de Pensamiento Iberoamericano, No. 2., PP. $271-284$.

Castillejo Cuéllar, A. (2007). La globalización del testimonio: historia, silencio endémico y los usos de la palabra. En: Revista Antípoda No. 4, enero-junio, PP. 76 - 99.

Flick, U. (2004). Introducción a la investigación cualitativa. Ediciones Morata y Fundación Paideia, Madrid y A Coruña.

Forer, A. (2011). Tentativa de una cuarta sentencia en Justicia y Paz. En: El Espectador, 24 de junio de 2011, Bogotá.

Gaborit, M. (2006). Memoria histórica: revertir la historia desde las víctimas”. En Gómez Isa, F. "El derecho a la memoria. Giza Eskubideak, derechos humanos. Bilbao.

Galtung, J. (1998). Tras los conflictos Tres R: Resolución, Reconstrucción, Reconciliación. Gernica Goguratuz, Vitoria.

Gibson, J.L. (2005). The Truth About Truth and Reconciliation in South Africa. En: International Political Science Review, Vol. 26, No. 4, 341-361.

Giraldo, Javier (2009). Carta Abierta de Objeción de Conciencia a la Fiscalía. En www.dhjusticiaypaz.com. Bogotá.

Gómez Isa, F. (2006). El derecho de las víctimas a la reparación por violaciones graves y sistemáticas a los derechos humanos. En: Gómez Isa, F. (Dir.) El derecho a la memoria. Giza Eskubideak Derechos Humanos, Bilbao.

González, F; Bolivar I, Vásquez, T. (2002). Violencia Política en Colombia. De la nación fragmentada a la construcción del Estado. CINEP. Bogotá.

Hamber, B. (1997). Living with the legacy of impunity: Lessons for South Africa about truth, justice and crime in Brazil. En: Latin American Report, Vol. 13, No. 2, PP. 4-16. 
Hamber, B (1998). The burdens of truth: An evaluation of the psychological support services and initiatives undertaken by the South African Truth and Reconciliation Commission. American Imago, Vol. 55, No. 1, PP. 9 - 28.

Hamber, B. (2000). Repairing the irreparable: dealing with the double-binds of making reparations for crimes of the past. En: Ethnicity and Health, Vol. 5, No. 3/4, PP. $215-$ 226.

Hamber, B. (2011). Transformar las sociedades después de la violencia política. Verdad, reconciliación y salud mental. Instituto Catalán Internacional para la Paz. Barcelona.

Hamber, B., Nagen, D. \& O'Malley, G. (2000). “Telling it like it is...": Understanding the truth and reconciliation commission from the perspective of survivors. En: Psychology in Society (PINS), No. 26, PP. 18-62.

Hamber, B. \& Wilson, R. (2002). Symbolic Closure through memory, reparation and revenge in post-conflict societies. En: Journal of Human Rights, Vol. 1, No. 1, Marzo.

Hayner, P. (2008). Verdades innombrables. Fondo de Cultura Económica. México D.F.

Huyse, Luc (2003). The Process of Reconciliation. En: Bloomfield, D., Barnes, T. and Huyse, L. (Eds.) Reconciliation After Violent Conflict, A Handbook. International IDEA. Stockholm.

Insuasty Rodríguez, A., Cadavid Acevedo, P., Restrepo Medina, L. P., Balbín Álvarez, J. W., \& Fernández Quintero, M. (2012). Víctimas, violencia y despojo: informes de la investigación acerca de víctimas del conflicto armado. Litoimpacto. Medellín. Colombia.

Insuasty Rodríguez, A., Balbín Álvarez, J. W., Bastidas Lopera, W., Carrión, J., Pineda, J. E., \& Mejía, W. (2012). Victimas en contextos de violencia e impunidad: caso Medellin. IPC. Medellín. Colombia.

Kiza, E.; Rathgeber, C.; Rohne, H.C. (2006). Victims of War: an empirical study on warvictimization and victims attitudes toward addressing atrocities. Hamburg institute for social research, Hamburg, Germany.

Laplante, L. \& Theidon, K. (2007). Después de la verdad: Demanda para reparaciones en el Perú poscomisión de la verdad y la reconciliación. En Revista Antípoda, No. 4, EneroJunio. PP. $119-145$.

Lederach, J.P. (1998). Construyendo la paz. Reconciliación sostenible en sociedades divididas. Bakaez, Gernika Gogoratuz. Bilbao.

Lira, E. (1998). "Recordar es volver a pasar por el corazón". En Páez, D.; Pennebaker, J.; Rimé B.; y Jodelet, D. (Eds.) Memorias colectivas de procesos culturales y políticos". Servicio Editorial de la Universidad del País Vasco, Bilbao. 
Lira, E. (2009). La resistencia de la memoria: Olvidos jurídicos y memorias sociales. En: Vinyes, R. (Ed.) El Estado y la memoria: Gobiernos y ciudadanos frente a los traumas de la historia. PP. $67-115$. Memorial Democratic, RBA Libros, Barcelona.

López, M. (2003). Transiciones y Reconciliaciones en la Agenda Global. En Seminario Internacional Reconciliación y Justicia en la Construcción de la Paz. Universidad Central, Bogotá.

Lykes, M. B., Martin Beristain, C., Cabrera, M. L. (2007). "Political violence, impunity and emotional climate in maya communities". En: Journal of Social Issues, Vol. 63, No. 2, PP. 369-385.

Mack, H. (2007). Justicia transicional en Guatemala: la confrontación política y la crisis de gobernabilidad diluyen las opciones de examinar el pasado. En: Serie Enfrentando el pasado. El legado de la verdad: impacto de la justicia transicional en la construcción de democracia en América Latina. ICTJ, Bogotá.

Martin-Baró (1991). El Latino Indolente. En "Psicología de la Liberación”. Ed Trotta, Madrid, 1998.

Martín Beristain, C (2000). "Justicia y Reconciliación: El papel de la verdad y la justicia en la reconstrucción de sociedades fracturadas por la violencia”. Bilbao: Cuadernos de Trabajo Hegoa.

Martin Beristain, C. (2005). Procesos de duelo en las comunidades mayas afectadas por violencia política. Tesis en psicología social. Facultad de Psicología, Universidad del País Vasco, Bilbao.

Martin Beristain, C. (2006). "Reconciliación Luego de Conflictos Violentos: un marco teórico". En "Verdad, Justicia y Reparación, desafios de la democracia y la conviviencia social". IDEA e IDH. San José de Costa Rica.

Martín Beristain, C. (2007a). Las comisiones de la verdad en América Latina. Una valoración de su impacto. En: El legado de la Verdad: Impacto de la justicia transicional en la construcción de la democracia en América Latina. ICTJ, Bogotá.

Martín Beristain, C. (2007b). Reconstrucción del tejido social. Aprendizajes y desafíos desde la experiencia guatemalteca. En: El legado de la Verdad: Impacto de la justicia transicional en la construcción de la democracia en América Latina. ICTJ, Bogotá.

Martin Beristain, C (2008). "Memoria colectiva y reconstrucción de sociedades fracturadas por la violencia". En Romero, M. (Ed.) "Verdad, memoria y reconstrucción: Estudios de caso y análisis comparado". Centro Internacional de Justicia Transicional (ICTJ). Bogotá.

Martín Beristain, C. (2009). Diálogos sobre la reparación. Qué reparar en los casos de violaciones de derechos humanos. Ministerio de Justicia y Derechos Humanos. Quito, Ecuador. 
Martín Beristain, C. (2010). El derecho a la reparación en los conflictos socioambientales. Hegoa y Universidad del País Vasco, Bilbao.

Martín Beristain, C \& Riera, F (1994). "Afirmación y Resistencia. La comunidad como apoyo". Virus editorial. Barcelona.

Martin Beristain, C. \& Pérez Sales, P. (2008). Trauma, development and peace building: a Latin American perspective. . Incore - IDRC, Unisersity of Ulster, Belfast.

Martín Beristain, C., Páez, D., Rimé, B. \& Kanyangara, P. (2010). Los efectos psicosociales de los rituales de justicia transicional: un análisis colectivo y una revisión de los estudios sobre los efectos de las Comisiones de Verdad y de los juicios sobre violaciones de los derechos humanos en América Latina. En: Revista de Psicología Social, Vol. 25, No. 1, PP. $47-60$.

Naraghi, S.; Conaway, C.P. \& Kays L. (2005a). Justicia de Transición y Reconciliación. En Seguridad Inclusiva, Paz Perdurable: Caja de Herramientas para la promoción y la acción. Women Waging Peace. UNIFEM.

Naraghi, S. Conaway, C.P. \& Kays, L. (2005b). Desarme, Desmovilización y Reintegración. En Seguridad Inclusiva, Paz Perdurable: Caja de Herramientas para la promoción y la acción. Women Waging Peace. UNIFEM.

Páez, D. (2010). Políticas oficiales de perdón y mejoría de las relaciones intergrupales: una aproximación neodurkheimiana a los perdones oficiales como riutales. Revista de Psicologia Social, Vol. 25, No. 1, Fundación Infancia y Aprendizaje.

Páez, D. \& Basabé, N. (1993). Trauma político y memoria colectiva: Freud, Halbwachs y la psicología política contemporánea. En Revista de Psicología Política, No. 6, Pp. 7 - 34. Valencia.

Páez, D. \& Liu, J. (2010). Collective Memories of Conflicts. In D. Bar-Tal (Ed.). Intergroup conflicts and their resolution: Social psychological perspective. New York: Psychology Press.

Pécaut, D. (2003). Violencia y política en Colombia. Elementos de reflexión. Hombre Nuevo Editores. Medellin, Colombia.

Piper, I. (2005). Obstinaciones de la Memoria: la dictadura militar chilena en las tramas del recuerdo. Tesis doctoral, Departamento de Psicología Social de la Universidad Autónoma de Barcelona.

Piper, I. (2009). Investigación y acción política en prácticas de memoria colectiva. En: Vinyes, Ricard (2009) El Estado y la memoria: Gobiernos y ciudadanos frente a los traumas de la historia. PP. 151-172. Memorial Democratic, RBA Libros, Barcelona.

Reyes Mate (2003). Memoria de Auschwitz. Editorial Trotta, Madrid. 
Sikkink, K. \& Booth Walling, C. (2007). The Impact of Human rights in Latin America. En: Journal of Peace Research, Vol. 44, No. 4, PP. 427 - 445.

Simon, J.M. (2005). Violencia masiva patrocinada por el Estado. Responsabilidad criminal y reconciliación. En: Boletín Mexicano de Derecho Comparado, nueva serie, año XXXVIII, No. 12, PP. 273-292.

Teubal, R.; Veiga, C. \& Bettanin, C. (2005). Familiares de desaparecido en la sombra: las voces de los hermanos. En: Cuadernos de Trabajo Social, vol. 18, PP. 181-195.

Uribe, M.V. (coord.) (2010). Memoria en tiempos de guerra: repertorio de iniciativas. Investigación del grupo de memoria histórica de la Comisión Nacional de Reparación y Reconciliación. Puntoaparte Editores. Bogotá.

Vandegiste, Stef (2003). Reparation. En: Bloomfield, D., Barnes, T. and Huyse, L. (Eds.) Reconciliation After Violent Conflict, A Handbook. International IDEA. Stockholm.

Viaene, L. (2008). Justicia Transicional y Contexto Cultural en Guatemala: Voces Q'eqchi'es sobre el Programa Nacional de Reparaciones. En: La Vida NO tiene precio: acciones y omisiones del Resarcimiento en Gautemala.

Villa, J.D. (2012). El papel de la memoria colectiva en el empoderamiento colectivo de las víctimas. Tesis Doctoral, Instituto de Estudios sobre Migraciones, Universidad Pontifica de Comillas, Madrid.

Villa, J.D. Tejada, Carolina; Sánchez, Nathalie \& Téllez, Ana María. (2007). Nombrar lo innombrable: Reconciliación desde la perspectiva de las víctimas. CINEP, Bogotá.

Yzerbyt, V. Y. \& Demoulin, S. (2010). Intergroup relations. En: Fiske, S. T.; Gilbert, D. T. \& Lindzey, G. (Eds.) Handbook of Social Psychology (5th edition). PP. $1024-1083$. Wiley, Hoboken, NJ.

Notas

${ }^{2}$ Es fundamental anotar que la investigación se realiza en el año 2011 y la primera mitad del 2012, cuando no se había desplegado y desarrollado plenamente el marco institucional que propone la ley de víctimas para la reparación integral. Por lo tanto, es importante tener claro que sus conclusiones se enmarcan dentro de las acciones previas (Ley de justicia y paz; decreto 1290 de 2008, de reparación administrativa; y las primeras acciones de la UARIV destinadas a cumplir los compromisos pendientes de la ejecución de indemnizaciones pendientes del decreto 1290 de 2008). Por lo tanto, y será propuesta de este artículo, al final del mismo, la necesidad de contrastar estos resultados con nuevas investigaciones que permitan hacer seguimiento a los procesos de reparación "integral" definidos por la ley 1448 de 2011, que se han empezado a implementar y desarrollar.

${ }^{3}$ Son leyes que tienen un marco filosófico donde aparentemente se recogen todas las recomendaciones y tratados internacionales del derecho de las víctimas. Sin embargo, en lo práctico, no se otorgan herramientas jurídicas reales para que la gente pueda satisfacer estos derechos. Con lo que al final se termina promoviendo una impunidad "formalmente" velada. En realidad no hay sanciones judiciales ni hay verdad. El balance en términos 
de justicia transicional, más allá del papel, es paupérrimo en términos de garantía de derechos. Además de ello: "el proceso judicial de justicia y paz no es el escenario adecuado para garantizar el derecho a la reparación a las víctimas del conflicto armado en Colombia, y mucho menos lo es para garantizar el derecho a la reparación colectiva" (Forer, 2011).

${ }^{4}$ Teniendo en cuenta, que tal y como se ha planteado desde el comienzo, se hace necesaria una nueva investigación que permita valorar los correctivos que el Estado, en múltiples escenarios públicos, dice haber desarrollado en pro de una reparación integral con la entrada en vigencia y la aplicación concreta de la ley 1448 de 2011. Esta nueva investigación nos permitirá aclarar este panorama y tener una visión más amplia de los significados que las víctimas y sus organizaciones están dando a los procesos de reparación.

${ }^{5}$ Y con realizar una asesoría para una "buena" inversión de ese dinero...

${ }^{6}$ El Estado afirma que esto se está viendo revertido con la aplicación de la ley 1448, se tendrá que avanzar hacia investigaciones que permitan confrontar esta situación. Sin embargo, si nos atenemos a la ponencia presentada por la representante Angela María Robledo en la comisión 5ta. de la Cámara el 15 de octubre de 2013, se dista mucho aún de dar cumplimiento a una reparación integral.

7(Páez \& Basabe, 1993; Hamber \& Wilson, 2002; Teubal, Vesga \& Bettanin, 2005; etc.).

${ }^{8}$ Ley 975 de 2005 (ley de justicia y paz) y ley 1424 de 2010 que regula la situación jurídica de los desmovilizados. 